\title{
A narrative review of COVID-19: magnesium isoglycyrrhizinate as a potential adjuvant treatment
}

\author{
Chuanfeng Tang ${ }^{1 \# \wedge}$, Hong Ding ${ }^{1 \#}$, Yang Sun ${ }^{1}$, Zhujun Han ${ }^{2}$, Lingdong Kong ${ }^{1}$ \\ ${ }^{1}$ State Key Laboratory of Pharmaceutical Biotechnology, School of Life Sciences, Nanjing University, Nanjing, China; ${ }^{2}$ Department of Pharmacy, \\ Affiliated to Dongtai Hospital of Nantong University, Dongtai, China \\ Contributions: (I) Conception and design: L Kong, Z Han, C Tang; (II) Administrative support: L Kong, Z Han; (III) Provision of study materials or \\ patients: All authors; (IV) Collection and assembly of data: C Tang, H Ding; (V) Data analysis and interpretation: L Kong, C Tang, H Ding; (VI) \\ Manuscript writing: All authors; (VII); Final approval of manuscript: All authors. \\ \#These authors contributed equally to this article. \\ Correspondence to: Prof. Lingdong Kong. State Key Laboratory of Pharmaceutical Biotechnology, School of Life Sciences, Nanjing University, \\ Nanjing 210023, China. Email: kongld@nju.edu.cn; Zhujun Han, Associate chief pharmaceutist. Department of Pharmacy, Affiliated to Dongtai \\ Hospital of Nantong University, Dongtai 224200, China. Email: dryhzj@163.com.
}

\begin{abstract}
Coronavirus disease 2019 (COVID-19) has become a global pandemic affecting more than 200 countries with 87 million patients worldwide as of January 7, 2021. Severe acute respiratory syndrome coronavirus-2 (SARS-CoV-2) replicates in a large amount and reaches high-titer levels in a short time after the infection. COVID-19 caused by SARS-CoV-2 shows clinical symptoms mainly including fever, fatigue, dry cough, and dyspnea. In more severe COVID-19 patients, viral pneumonia characterized by bilateral ground glass or patchy opacity, may lead to acute respiratory distress syndrome (ARDS), cytokine storm, multi-organ damage, and even death. Unfortunately, there is no effective therapy for COVID-19 until now. Magnesium isoglycyrrhizinate (MgIG), a magnesium salt of 18- $\alpha$ glycyrrhizic acid stereoisomer, belongs to the fourth generation of glycyrrhizic acid preparation. MgIG has various pharmacological activities including anti-inflammation, anti-oxidation, anti-virus, and immunoregulation, showing the protection against the injury of the vital organs (such as kidney, heart, and lung). Clinically, MgIG injection is usually used as a hepatoprotective agent to treat liver diseases. This narrative review summarizes the research and application of $\mathrm{MgIG}$, and provides the evidence supporting the recommended $\mathrm{MgIG}$ as supportive therapy in the "Management Standard for Mild and Common Patients of Coronavirus Disease 2019 (COVID-19) (Second Edition)", which is jointly issued by National Health Commission of People's Republic of China and National Administration of Traditional Chinese Medicine.
\end{abstract}

Keywords: Magnesium isoglycyrrhizinate (MgIG); COVID-19; cytokine storm; multiple organ damage; anti-virus

Submitted Oct 12, 2020. Accepted for publication Jan 14, 2021.

doi: 10.21037/apm-20-1971

View this article at: http://dx.doi.org/10.21037/apm-20-1971

\section{Introduction}

Coronavirus disease 2019 (COVID-19) outbreak with the infection of severe acute respiratory syndrome coronavirus 2 (SARS-CoV-2), has caused worldwide pandemic transmission by human-to-human rapidly. As of January
7, 2021, the total number of infected people confirmed has reached more than 87 million, and global deaths have exceeded 1 million. COVID-19 carries a mortality of approximately $3.02 \%$ (WHO reported). The mortality rate of COVID-19 patients from 5 to 17 years old is about

^ ORCID: 0000-0001-9811-8450. 
Table 1 Development of glycyrrhizic drugs

\begin{tabular}{llll}
\hline Generations & Medicine & Product name & Main ingredient \\
\hline First & Glycyrrhizin & Potenlin & $\begin{array}{l}\text { Monoammonium Glycyrrhizinate, L-Cysteine } \\
\text { hydrochloride, Glycine }\end{array}$ \\
Second & Compound Glycyrrhizin & Stronger Neo-Minophagen C & Glycyrrhizin, Glycine, DL-Methionine \\
& Compound Ammonium Glycyrrhetate & Maineng & Monoammonium Glycyrrhizinate, Glycine, \\
& Diammonium glycyrrhizinate & Ganlisin & L-Cysteine hydrochloride \\
Third & & & $\begin{array}{l}\text { Isomer mixture preparation of } 18 \alpha-g l y c y r r h i z i c \\
\text { and } 18 \beta \text {-glycyrrhizic acid }\end{array}$ \\
Fourth & Magnesium isoglycyrrhizinate & Tianqing Ganmei & $18 \alpha-$ glycyrrhizic acid content above 97\% \\
\hline
\end{tabular}

$0.30 \%$, and that of the patients over 85 years old is about $30.49 \%$. Among patients admitted to the intensive care unit, the case fatality rate is as high as $40 \%$ in the US (1).

The SARS-CoV-2 shortly replicates in a large amount and reaches high-titer levels in the early and advanced stages of the disease (2). When the infection is out of control, cytokine storm (an uncontrolled inflammatory response) occurs. Cytokine storm is characterized by excessive activation and release of inflammatory factors and chemokines including interleukin-1 $\beta$ (IL-1 $\beta$ ), IL-2, IL-6, IL-7, IL-10, monocyte chemoattractant protein-1 (MCP1), tumor necrosis factor- $\alpha$ (TNF- $\alpha)$, IL-4, interferon- $\gamma(\mathrm{IFN}-\gamma)$, macrophage inflammatory protein 1 alpha (MIP-1 $\alpha$ ), MIP-1 $\beta$, granulocyte-colony stimulating factor $(\mathrm{G}-\mathrm{CSF})$, etc. $(3,4)$. This cytokine storm is related to the deterioration of many infectious diseases with severe acute respiratory syndrome (SARS) (5), and Middle East respiratory syndrome (MERS) (6). Of note, in the early stage of SARS-CoV-2 infection, early inflammatory response with high serum levels of IL-1 $\beta$, IL-2, and IL-7 are observed in COVID-19 patients $(3,7)$. Patients with moderate to severe COVID-19 show a cytokine storm $(2,7)$, which causes pathological changes of the respiratory system (8-11), and leads to extrapulmonary manifestations, mainly liver injury (12), myocardial dysfunction (13), acute kidney injury (14), hyperglycemia and ketosis (9), as well as complications of immunological, hematological, nervous and gastrointestinal systems (7,15-18). Therefore, both cytokine storm and multiple organ damage are major reasons resulting in COVID-19 patients condition deterioration and even death. Effective drugs are needed urgently for COVID-19 therapy.

Traditional Chinese herbal medicine has achieved certain effects in the treatment of COVID-19 patients in China. Gancao (Glycyrrbizae Radix et Rbizoma), is one of the main representative medicine (19-21). Recent studies have shown that its main active ingredient glycyrrhizic acid is a promising candidate of COVID-19 (22-27). This compound has anti-virus (28), anti-inflammation (29), anti-bacteria (30), modulation of immune function and gut microbiota $(31,32)$, protection of liver, kidney and heart (32-35). Due to the clinical urgent need, glycyrrhizic acid preparations have undergone four generations of development, including the first-generation of glycyrrhizin preparation, the second-generation of compound glycyrrhizin and compound ammonium glycyrrhizate, the third-generation of diammonium glycyrrhizinate and diammonium glycyrrhizinate liposomes, and further modified and optimized fourth-generation of magnesium isoglycyrrhizinate (MgIG) injection (Table 1).

MgIG is a magnesium salt mainly composed of $18 \alpha$-glycyrrhizic acid stereoisomers (Figure 1). Its injection is a new drug for viral hepatitis treatment independently developed in China. Clinical trials and basic researches have shown that MgIG has anti-inflammatory, antioxidant, antiviral, immunomodulatory and hepatocyte protective effects (37-40). Meanwhile, a series of studies have shown that MgIG has good intervention effects on kidney, heart, lung and brain -related diseases, protecting the function of these organs and tissues (38-47). Therefore, MgIG injection is often used in clinical treatment of various diseases. On the other hand, MgIG as the latest preparation of glycyrrhizic acid has stable pharmacological activity and high safety, which should be considered for supportive treatment of COVID-19 patients. In this narrative review, we introduce the research progress of $\mathrm{MgIG}$ and provide evidence to support the use of MgIG in the treatment of COVID-19.

We present the following article in accordance with the Narrative review checklist (available at http://dx.doi. org/10.21037/apm-20-1971). 


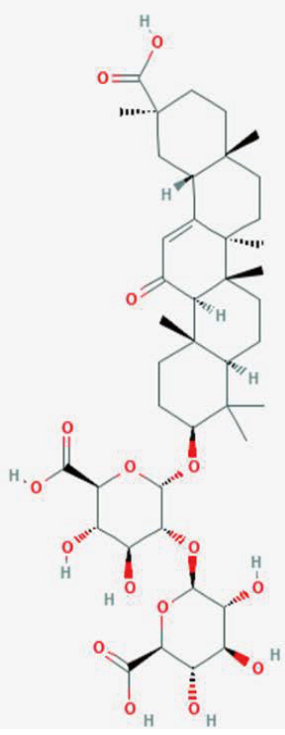

Glycyrrhizic acid

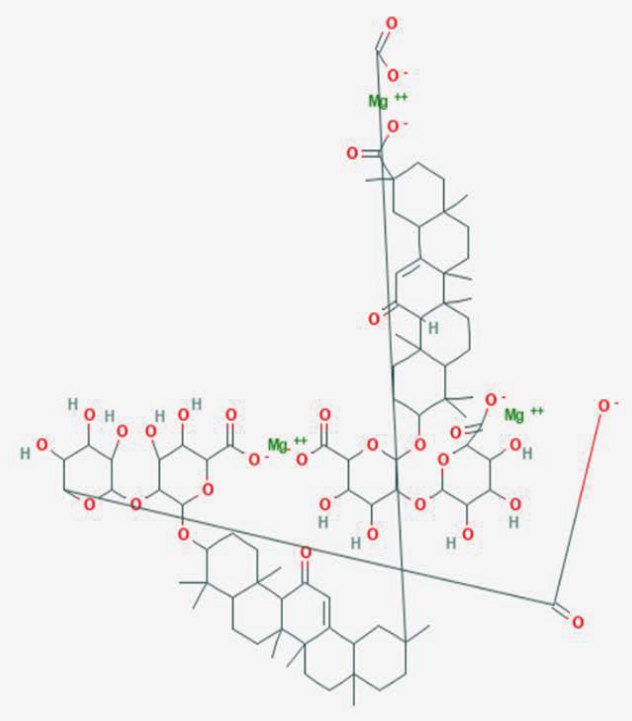

Magnesium isoglycyrrhizinate

Figure 1 Structure of Glycyrrhizic acid and magnesium isoglycyrrhizinate (36).

\section{Protecting vital organs}

\section{Liver}

Clinical risk factors (virus infection, drug- or alcoholinduced hepatitis or coronavirus-induced cytokine storm, etc.) cause abnormal liver function in patients. MgIG effectively prevents and treats liver diseases such as viral hepatitis, drug hepatitis, alcoholic hepatitis, and liver fibrosis possibly through inhibiting transcription factor kappa B (NF- $\mathrm{B})$, IL-6, tyrosine protein kinase 2/signal transducer and transcription activator 3 (JAK2/STAT3) signaling pathways.

\section{Viral hepatitis}

Viral hepatitis is an infectious disease caused by hepatitis viruses. On the basis of conventional treatment, the combination of glycyrrhizic acid preparations such as compound ammonium glycyrrhizinate, diammonium glycyrrhizinate and MgIG can more effectively inhibit viral replication, improve liver function, and increase clinical effectiveness for the treatment of viral hepatitis in clinic (48-50). Especially, the fourth-generation MgIG injection can accelerate the recovery of liver function in patients $(51,52)$. For patients with chronic hepatitis B, after 2 and 4 weeks of MgIG injection treatment, alanine aminotransferase (ALT), aspartate aminotransferase (AST), total bilirubin (TBIL), and $\gamma$-glutamyl transpeptidase $(\gamma-\mathrm{GT}$ ) levels in serum are lower than that before treatment (53). Furthermore, combined use of MgIG injection (150 mg, iv qd) and adefovir is beneficial to inhibit virus proliferation and enhance immunity than adefovir administration group alone in patients with hepatitis B (53). MgIG also enhances the antiviral efficacy of nucleoside analogues treatment and help to improve liver function (50). Lamivudine is often used for the treatment of adult chronic hepatitis B patients with compensatory liver function accompanied by elevated ALT and viral activity replication. MgIG injection (150 mg, iv qd) in combination with lamivudine on chronic hepatitis $B$ is beneficial to the continued decline of HBV viral load, and decreases serum ALT levels (49). Of note, studies of MgIG on viral hepatitis are mostly clinical trials, but the corresponding basic experiments are scarce. The mechanism for hepatoprotective effects of MgIG in the setting of hepatitis is worthy of further exploration.

\section{Drug-induced hepatitis}

MgIG effectively treats drug-induced hepatitis. It reduces serum ALT and AST levels, and improves liver function and prognosis of patients with drug-induced hepatitis (54). A randomized, double-blind, multi-doses, active drug controlled, multicentre phase II trial in China show that, compared with control group (Tiopronin, for early treatment of viral hepatitis, alcoholic hepatitis, drug-induced hepatitis, heavy metal toxic hepatitis, severe 
hepatitis and liver cirrhosis, as standard therapy for liver injury in China), low-dose (200 mg iv, qd) and high-dose (400 mg iv, qd) of MgIG injection produce better curative effect in the early stage as well as 4-week treatment, showing that the proportion of ALT normalization is significantly greater in 174 patients with eligible liver injury. These results clearly demonstrate that $\mathrm{MgIG}$ injection is used as an effective strategy for the treatment of drug-induced liver injury (55).

Basic researches initially reveal the potential mechanism of $\mathrm{MgIG}$ intervention in drug-induced liver injury. Methotrexate has limited clinical application due to its hepatoenteric toxicity. Prophylactic administration of MgIG (9 or $18 \mathrm{mg} / \mathrm{kg}$ ip, qd) can effectively attenuate methotrexate-induced liver fibrosis and hepatotoxicity damage in mice (56). MgIG decreases serum ALT and AST levels, down-regulates liver cyclooxygenase-2 expression, and reduces liver collagen deposition in these animals (56). MgIG (15 or $45 \mathrm{mg} / \mathrm{kg}$ ip, qd) also prevents oxaliplatininduced liver injury. It inhibits mRNA and protein expression of liver metallothionein 1 , peroxiredoxin 1 , superoxide dismutase 2, IL-6 and STAT3, and suppresses mRNA and protein expression of liver von Willebrand factor, plasminogen activator inhibitor- 1 in this animal model, thus showing its attention of liver injury-related oxidative stress, IL-6 pathway activation and coagulation system disturbances (57).

Consistently, in oxaliplatin-exposed L-02 cells, MgIG (40 or $100 \mu \mathrm{M}$ ) significantly attenuates the expression abnormality of metallothionein 1, peroxiredoxin 1 and superoxide dismutase 2, as well as IL-6 secretion. In addition, MgIG $(13.5 \mathrm{mg} / \mathrm{kg}$ intragastric administration, $\mathrm{qd})$ can upregulate mRNA and protein levels of the nuclear factor erythroid 2-related factor $2(\mathrm{Nrf} 2)$, and activate $\mathrm{Nrf2}$-related antioxidant pathway to reduce hepatotoxicity caused by triptolide in rats (35). Of note, $\mathrm{MgIG}$ also ameliorate doxorubicin-induced acute hepatotoxicity via anti-oxidant and anti-apoptotic mechanisms in mice (58). MgIG significantly increases superoxide dismutase (SOD) and glutathione peroxidase and decreases malondialdehyde (MDA) levels in serum, and down-regulates liver expression levels of apoptosisrelated proteins $\mathrm{Bax} / \mathrm{Bcl}-2$, and caspase- 3 in doxorubicintreated mice (58). $\mathrm{MgIG}(25,50,100$, and $200 \mathrm{mg} / \mathrm{kg}$ ip, qd) reduces serum ALT levels, and protects against docetaxelinduced liver injury in mice (40). Additionally, MgIG (25, and $50 \mathrm{mg} / \mathrm{kg}$ ip, qd) can reduce cyclophosphamide-induced liver injury by inhibiting NF- $\kappa \mathrm{B}$-mediated inflammation and phosphatidylinositol 3-kinase/protein kinase B (PI3K/Akt) axis-mediated autophagy in mice (59).

\section{Alcoholic liver injury}

Long-term excessive alcohol drinking is the main reason for high morbidity and mortality of liver diseases worldwide. MgIG alone or in combination with other drugs can help treat alcoholic hepatitis. MgIG injection (200 mg iv, qd) is reported to significantly reduce serum AST, ALT, direct bilirubin (DBIL) and glutamyltransferase (GCT) levels in patients with alcoholic hepatitis, showing an enhanced therapeutic effect when combined with glutathione $(60,61)$.

In mouse model of the chronic plus binge ethanol feeding, MgIG (22.5 or $45 \mathrm{mg} / \mathrm{kg}$ ip, qd) can lower serum ALT and AST levels, reduce neutrophil reactive oxygen species (ROS) production, and inhibit proinflammatory cytokine secretion, thereby preventing liver damage (62). Meanwhile, MgIG (5 mg/mL) inhibits the transduction of hedgehog signaling pathway, which is related lipometabolic genes [such as peroxide enzyme proliferators activate receptor $\alpha(\mathrm{PPAR} \alpha)$ and cholesterol regulatory element binding protein 1c (SREBP-1c)] as well as oxidationrelated genes (such as ROS, SOD), to prevent steatosis, oxidative stress, mitochondrial dysfunction, and apoptosis in hepatocytes (63). However, more studies are needed to explore possible molecular mechanisms by which MgIG protects from alcoholic hepatitis.

\section{Liver fibrosis and others}

In animal model of carbon tetrachloride $\left(\mathrm{CCl}_{4}\right)$-induced liver fibrosis, $\mathrm{MgIG}(15,30$ or $45 \mathrm{mg} / \mathrm{kg}$ ip, qd) markedly prevents hepatic injury and reduces fibrotic scar formation, further results from in vitro experiments show that the anti-fibrosis effect of $\operatorname{MgIG}(2.5,5,10 \mathrm{mg} / \mathrm{mL})$ may be associated with its regulation of hepatic stellate cell (HSC) ferroptosis via a heme oxygenase-1 (HO-1) dependent mechanism (64). Similarly, MgIG (2.5, 5 or $10 \mathrm{mg} / \mathrm{mL})$ is reported to suppress HSCs proliferation and induce cell cycle arrest, and then stimulate endoplasmic reticulum stress-induced apoptosis in activated HSCs, which are consistent with its attenuation of $\mathrm{CCl}_{4}$-induced liver fibrosis in mice treated with $\mathrm{MgIG}(60 \mathrm{mg} / \mathrm{kg}$ ip, qd) (65). Additionally, $\mathrm{MgIG}(15,30$ or $60 \mathrm{mg} / \mathrm{kg}$ ip, qd) alleviates $\mathrm{CCl}_{4}$-induced liver fibrosis and inflammation in mice, possibly by reducing transforming growth factor- $\beta \mathrm{R} 1$ (TGF- $\beta R 1$ ), platelet derived growth factor- $\beta \mathrm{R}$ (PDGF$\beta \mathrm{R}$ ), and tumor inhibitor of metalloproteinase 1 (TIMP1) expression, and increasing matrix metalloproteinase-2 expression, indicating that MgIG can regulate two key profibrogenic pathways TGF- $\beta$ signaling and MMP/TIMP system to inhibit liver fibrosis (66). In fact, in TGF- $\beta 1$ - 
induced human HSCs LX2 fibrotic cell model, MgIG $(1 \mathrm{mg} / \mathrm{mL})$ reduces the production of $\alpha$-smooth muscle actin ( $\alpha \mathrm{SMA})$ and type I collagen, and inhibits extracellular regulated protein kinases (ERK) pathway to suppress the nuclear localization of Smad protein, resulting in decreased cell proliferation and increased senescence (66).

On the other hand, MgIG suppresses inflammation of liver fibrosis, with the down-regulation of TNF- $\alpha$, IL- $1 \beta$, IL-4, IL-6, IL-8, IL-10, and IL-18 levels, and the reduction of the proportion of Ly6 G positive cells, CD68 positive cells, and CD11b positive cells in vivo (67). Furthermore, $\operatorname{MgIG}(2.5,5$ or $10 \mathrm{mg} / \mathrm{mL})$ not only inhibits the expression of pro-inflammatory cytokines TNF- $\alpha$, IL-18, IL-8, IL-6, and IL- $1 \beta$, but also promotes the activation of HSC to produce anti-inflammatory cytokines IL-10 and IL-4, possibly through inhibiting Hippo/Yes-associated protein (Hippo/Yap) signaling pathway in primary HSCs cultured with recombinant mouse platelet derived growth factor-BB (PDGF-BB) (67).

MgIG also ameliorates metabolic syndrome-associated chronic liver injury and fibrosis. In high fructose-fed rats, $\operatorname{MgIG}(10,20$, and $40 \mathrm{mg} / \mathrm{kg}$ ip, qd) mitigates the pathological characteristics of metabolic syndrome and improves hepatocyte epithelial-mesenchymal transition and liver fibrosis by increasing liver miR-375-3p expression to inhibit JAK2/STAT3 pathway and TGF- $\beta 1 / \mathrm{Smad}$ signaling (68). It alleviates liver inflammation and lipid accumulation induced by high fructose diet possibly through inhibiting NF- $\kappa$ B/NLR family pyrin domain containing 3 (NLRP3) inflammasome activation and regulating lipid metabolism-related proteins PPAR $\alpha$, carnitine palmitoyl transferase-1, sensor for fatty acids to control-1 (SREBP-1) and stearoyl-CoA desaturase 1 (69). In concanavalin A-induced mouse autoimmune hepatitis model, MgIG (50 or $100 \mathrm{mg} / \mathrm{kg}$ ip, qd) can reduce serum AST and ALT levels, inhibit $\mathrm{CD} 4^{+} \mathrm{CD} 25^{-} \mathrm{CD} 69^{+}$subset proliferation and NLPR3 inflammasome activation to improve autoimmune hepatitis (70). In rat model with acute necrotizing pancreatitis through retrograde injection of $5 \%$ sodium taurocholate into the biliary-pancreatic duct, $\mathrm{MgIG}$ (30 mg/kg ig, qd) increases liver SOD levels, reduces MDA accumulation, and inhibits IL- $1 \beta$, and NF- $\kappa B$, showing its inhibition of oxidative stress and inflammatory response as well as attenuation of liver damage aggravation induced by high fat diet (71).

We summarized the therapeutic effects of MgIG on liver diseases and the possible mechanisms in Figure 2.

\section{Heart}

Cardiac hypertrophy is an independent risk factor for increasing cardiovascular disease mortality and threatens human (72,73). In isoproterenol-induced mouse model of myocardial injury, $\mathrm{MgIG}$ injection (25 or $50 \mathrm{mg} / \mathrm{kg}$ ip, qd) for 14 days lowers serum lactate dehydrogenase (LDH) and creatine kinase (CK) levels, and down-regulates heart expression of basic fibroblast growth factor (bFGF), proapoptotic gene (Bax), Toll-like receptor 4 (TLR4) and NF- $\mathrm{kB}$ p65, suggesting that MgIG may inhibit TLR4/ NF- $\kappa \mathrm{B}$ pathway to alleviate myocardial hypertrophy and fibrosis (43). Additionally, $\mathrm{MgIG}$ inhibits L-type $\mathrm{Ca}^{2+}$ currents $\left(\mathrm{I}_{\mathrm{Ca}-\mathrm{L}}\right)$ in a dose-dependent manner, and reduces the cell shortening and the peak of calcium transients at $0.3 \mathrm{mg} / \mathrm{mL}$ in rat cardiomyocytes, indicating that $\mathrm{MgIG}$ exerts the cardioprotective effects (74).

\section{Kidney}

The kidney is an important organ that affects blood composition, blood pressure regulation, and metabolism. Kidney diseases cause the imbalances in the body's water and electrolytes, metabolic acidosis, immune system or developmental abnormality, leading to kidney failure and death. MgIG has positive effects on patients with hemorrhagic fever with renal syndrome (HFRS) and renal ischemia-reperfusion injury. In HFRS patients, MgIG injection (100 $\mathrm{mg}$ iv, qd) is used as an effective method for decreasing serum ALT levels, shortening the hospitalization period and improving HFRS accompanied with liver injury (75). MgIG (30 mg/kg ip, qd) protects rats from renal ischemia-reperfusion injury through anti-inflammatory, anti-oxidation, anti-apoptosis effects. It reduces serum TNF- $\alpha$ and IL-1 $\beta$ and IL-6 levels, increases serum SOD and glutathione peroxidase (GSH-Px) activity, and inhibits serum inducible nitric oxide synthase (iNOS) activity and protein expression, suppresses renal caspase 3 activity as well as matrix metalloproteinase-2, STAT3 and intercellular adhesion molecule-1 (ICAM-1) protein expression in renal ischemia-reperfusion injury of rats (41). MgIG (10, 20 or $40 \mathrm{mg} / \mathrm{kg}$ ip, qd) is reported to significantly prevent renal dysfunction, proteinuria and podocyte apoptosis by the inhibition of miR-193a and the up-regulation of Wilms 


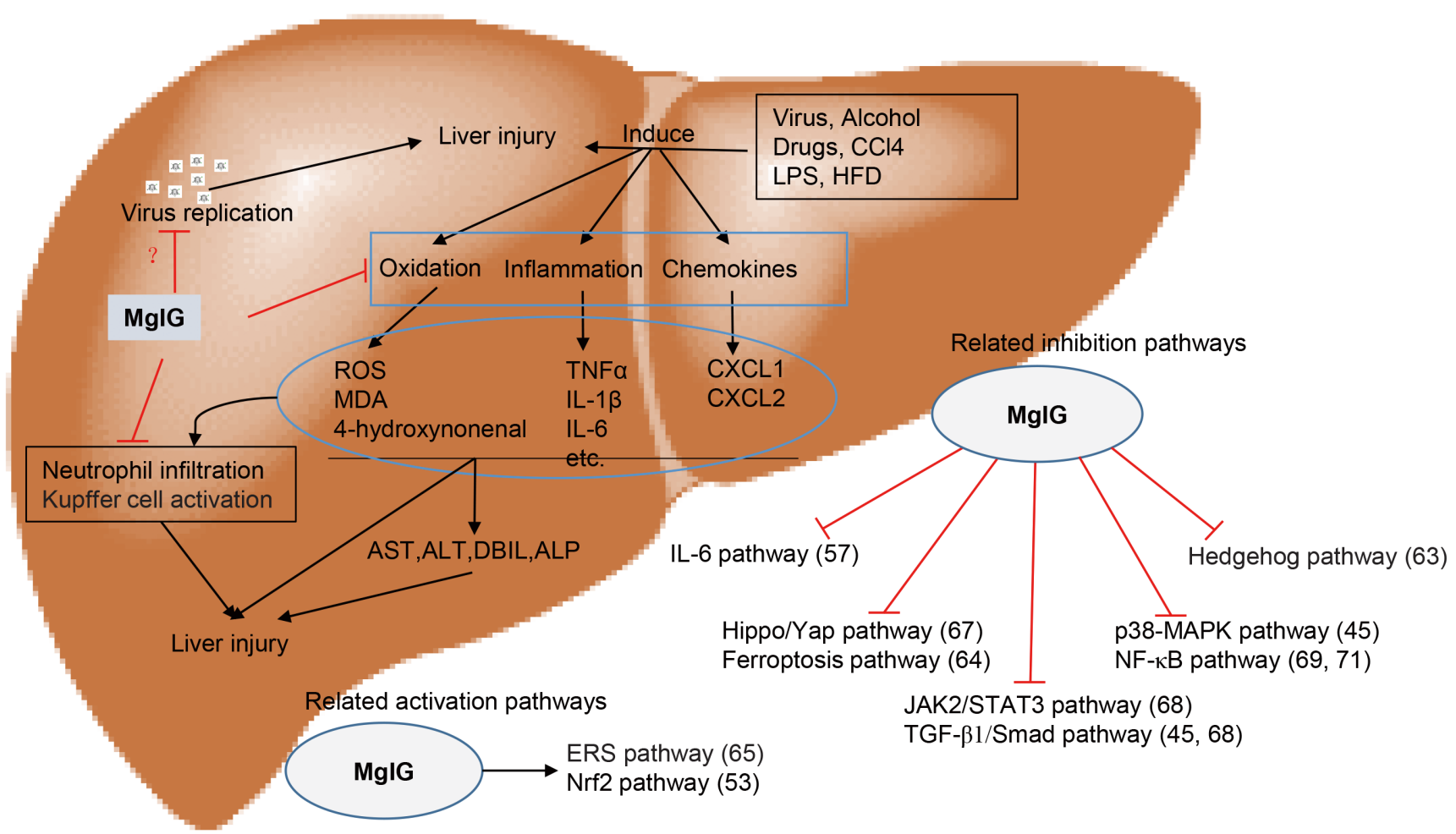

Figure 2 MgIG's effects on various liver diseases and possible mechanisms. MgIG has hepatoprotective properties mainly by inhibiting IL-6 pathway, Hippo/Yap pathway, and ferroptosis pathway, etc. $(45,57,63,64,67-69,71)$, and activating ERS pathway and Nrf2 pathway (53,65). MgIG, magnesium isoglycyrrhizinate; CCl4, carbon tetrachloride; LPS, lipopolysaccharide; HFD, high-fat diet; ROS, reactive oxygen species; MDA, malondialdehyde; TNF- $\alpha$, tumor necrosis factor- $\alpha$; IL- $1 \beta$, interleukin-1 $\beta$; CXCL, chemokine (C-X-C motif) ligand; AST, aspartate aminotransferase; ALT, alanine aminotransferase; DBIL, direct bilirubin; ALP, alkaline phosphatase; Hippo/Yap pathway, Hippo/ Yes-associated protein pathway; p38 MAPK, p38 adenosine 5'-monophosphate-activated protein kinase; NF- $\kappa \mathrm{B}$, transcription factor kappa B; JAK2, tyrosine protein kinase 2; STAT3, signal transducer and transcription activator 3; Smads, Sterile alpha motif domain-containing proteins; TGF- $\beta 1$, transforming growth factor $-\beta 1$; Nrf2, nuclear factor-erythroid 2-related factor-2; ERS, endoplasmic reticulum stress.

tumor protein 1 (WT1) in high fructose-fed rats (38).

\section{Lung}

The protective effect of $\mathrm{MgIG}$ on paraquat and radiationinduced pulmonary fibrosis is reported $(44,45)$. MgIG (100 mg/kg ip, qd) significantly reduces pulmonary tissue collagen deposition and serum TGF- $\beta 1$ levels in radiationinduced pulmonary fibrosis of mice (45). Furthermore, MgIG regulates p38 adenosine 5'-monophosphate (AMP)activated protein kinase/protein kinase $\mathrm{B} /$ nicotinamide adenine dinucleotide phosphate oxidase 4 (p38 MAPK/ Akt/NOX4) pathway to inhibit the differentiation of lung fibroblasts, thereby improving pulmonary fibrosis in this animal model (45). MgIG (15, 30 or $45 \mathrm{mg} / \mathrm{kg}$ ip, qd) also slow down the process of pulmonary fibrosis, with the reduction of serum and lung ICAM-1 and MMP9 expression in paraquat-induced lung injury of rats (44). These results provide experimental basis for the selection of MgIG for clinical treatment of lung diseases.

\section{Cognitive ability and depression-like behavior}

MgIG (25 or $50 \mathrm{mg} / \mathrm{kg}$ ip, qd) effectively alleviates the decline in spatial learning ability and memory ability in epirubicin-induced hepatic encephalopathy of mice. It reduces serum and hippocampal SOD activity, reduces MDA, TNF- $\alpha$, IL- 6 and IL- $1 \beta$ levels, down-regulates thioredoxin-interacting protein and $\mathrm{NF}-\kappa \mathrm{B}$ pathway, activates $\mathrm{Nrf} 2 / \mathrm{HO}-1 /$ Thioredoxin (TRX) axis in hippocampal region in this animal model (46). MgIG (25 or $50 \mathrm{mg} / \mathrm{kg} \mathrm{ig}, \mathrm{qd})$ significantly improves the immobile 
Table 2 Protective effects of magnesium isoglycyrrhizinate (MgIG) on organ and tissue injury of related diseases and its underlying mechanism

\begin{tabular}{|c|c|c|c|}
\hline Tissue & Diseases & Protective effects & Mechanism \\
\hline Kidney & $\begin{array}{l}\text { Kidney dysfunction, renal } \\
\text { ischemia-reperfusion injury }\end{array}$ & $\begin{array}{l}\text { Anti-inflammatory, antioxidant and } \\
\text { anti-apoptotic effects }\end{array}$ & $\begin{array}{l}\text { Inhibit iNOS, ICAM- } 1 \text { and MMP- } 2 \text { expression, } \\
\text { inhibit JAK2/STAT } 3 \text { and TGF- } \beta 1 / \text { Smads } \\
\text { signaling pathway }\end{array}$ \\
\hline Lung & Pulmonary fibrosis & $\begin{array}{l}\text { Inhibit fibroblast differentiation, } \\
\text { improve pulmonary fibrosis, reduce } \\
\text { collagen deposition, anti-inflammatory, } \\
\text { anti-oxidation, anti-apoptosis effects }\end{array}$ & $\begin{array}{l}\text { Inhibit p38 MAPK/Akt/NOX4 signaling } \\
\text { pathways, reduce the expression of ICAM-1 } \\
\text { and MMP-9 }\end{array}$ \\
\hline
\end{tabular}

Summarize the effects of magnesium isoglycyrrhizinate in part of "protecting vital organ". The references are consistent with the text, and will not be referred here. MgIG, magnesium isoglycyrrhizinate; TLR4, toll-like receptor 4; NF-kB, transcription factor kappa B; PI3K, phosphatidylinositol 3-kinase; Akt, protein kinase B; mTOR, mammalian target of rapamycin; JAK2, tyrosine protein kinase 2; STAT3, signal transducer and transcription activator 3; TGF- $\beta 1$, transforming growth factor $\beta$; Smads, sterile alpha motif domain-containing proteins; Hippo/Yap pathway, Hippo/Yes-associated protein pathway; Nrf2, nuclear factor erythroid 2-related factor 2; NOX4, nicotinamide adenine dinucleotide phosphate oxidase 4; ROS, reactive oxygen species; I $\mathrm{Ca}_{\mathrm{L}-\mathrm{L}}$, L-type $\mathrm{Ca}^{2+}$ currents; iNOS, inducible nitric oxide synthase; ICAM-1, intercellular adhesion molecule-1; MMP-2, matrix metallopeptidase-2; p38 MAPK, p38 adenosine 5'-monophosphate (AMP)activated protein kinase; TXNIP, thioredoxin-interacting protein.

time in the tail suspension test and forced swimming test in lipopolysaccharide-induced depressive-like behavior of mice (47). MgIG inhibits the rise of pro-inflammatory cytokines and oxidative stress in serum and hippocampus, mainly down-regulates p-JAK2, p-STAT3, p-NF- $\mathrm{BB}$ p65 and $\mathrm{p}-\mathrm{I} \kappa \mathrm{B} \alpha$ protein levels in hippocampus, suggesting that the inhibition of hippocampus JAK/STAT/NF- $\mathrm{kB}$ pathway may be related to its anti-depressant effects (47).

We summarized the protective effects of $\mathrm{MgIG}$ on organ and tissue injury of related diseases and its underlying mechanism (Table 2).

\section{Current treatment difficulties of COVID-19}

The new pneumonia COVID-19 that has recently erupted in many parts of the world is a severe acute respiratory disease caused by a novel coronavirus of the genus $\beta$. The novel coronavirus gene sequence has extremely high similarity with the SARS-CoV outbreak in 2003 and the MERS-CoV outbreak in 2012 (76). Thus, SARS-CoV-2 infects humans, and is listed as the seventh member of the coronavirus family (77).

At present, there are no specialized antiviral drugs for COVID-19 patients, and the widespread of SARS-CoV-2 causes a huge increase in the number of COVID-19 patients and the resulting deaths worldwide. Therefore, identifying effective antiviral agents to treat COVID-19 is of most urgency. The medications used for COVID-19 include remdesivir, chloroquine and hydroxychloroquine, tocilizumab, lopinavir/ritonavir, favipiravir, convalescent plasma therapy, azithromycin, vitamin $\mathrm{C}$, corticosteroids, interferon and colchicine (78-86).

Drugs that are hotly discussed in the scientific research and medical community for the treatment of COVID-19 mainly include remdesivir and chloroquine, both of them may cause side effects such as organ injury. Redoxivir has a wide range of antiviral activity against Ebola virus, zoonotic coronaviruses, Nipah virus, respiratory syncytial virus, etc. (87-90). However, its adverse reactions (such as nausea, vomiting, gastrointestinal symptoms, multiple-organ- 
dysfunction syndrome, septic shock, acute kidney injury and hypotension) cannot be ignored $(84,91)$. In the rhesus macaque model of SARS-CoV-2 infection, 12 hours after the first treatment of a $10 \mathrm{mg} / \mathrm{kg}$ intravenous injection of remdesivir, the viral load of the lower respiratory tract is reduced, while no reduction in viral shedding is observed, especially in the upper respiratory tract compared with control group. On the 7 th day after infection, the viral load in the lungs of rhesus macaques in the remdesivir group is significantly reduced, and the lung tissue injury is also significantly improved. Although remdesivir has shown obvious effects in alleviating respiratory symptoms and reducing virus replication in the lung in the treatment of rhesus macaques infected with SARS-CoV-2, the viral shedding of rhesus macaques during the period of carrying the virus has not been reduced, and it is still transmissible (92).

The therapeutic effect of chloroquine and hydroxychloroquine on COVID-19 is still controversial $(93,94)$. A prospective, observational study assesses the QT interval (calculated as the time from the start of the $\mathrm{Q}$ wave to the end of the $\mathrm{T}$ wave, and approximates to the time taken from when the cardiac ventricles start to contract to when they finish relaxing) of 211 COVID-19 patients treated with chloroquine/hydroxychloroquine. The use of chloroquine/hydroxychloroquine and azithromycin results in a significantly greater increase in the corrected QT interval when compared to monotherapy with either chloroquine or hydroxychloroquine, and a prolongation of the QT interval possibly increases the risk of Torsade de pointes and arrhythmogenic death (95). In a randomized trial which enrolled 821 participants of a post-exposure prevention study on SARS-CoV-2, hydroxychloroquine or placebo are given to subjects who have not taken appropriate protective measures but have close contact with COVID-19 patients for more than $10 \mathrm{~min}$. About $12 \%$ of people in the hydroxychloroquine group have COVID-19-related symptoms, but there is no statistically significant difference compared with $14 \%$ in the placebo group (85). These data suggest hydroxychloroquine has no obvious preventive effect for symptomatic infection after SARS-CoV-2 exposure. Furthermore, on the basis of standard treatment, the use of hydroxychloroquine does not significantly improve the probability of negative conversion of mild to moderate COVID-19 patients, but causes a higher incidence of adverse reactions than in nonrecipients, especially diarrhea, reported in 7/70 (10\%) patients in a multicentre, open label, randomized controlled trial of hydroxychloroquine (96).

In addition to existing drugs, clinical vaccines are also under continuous development, 30 (WHO reported) vaccines of the COVID-19 have entered clinical trials in the world, including inactivated virus vaccine, adenovirus vector vaccine, mRNA, DNA and recombinant protein vaccine (97). In the latest research, BNT162b1 developed by Pfizer is a lipid nanoparticle-formulated, nucleosidemodified, mRNA vaccine that encodes trimerized SARSCoV-2 spike receptor binding domain (RBD). Phase $1 / 2$ study shows that BNT162b1-induced SARS-CoV-2 neutralization titers reach 1.8- to 2.8-fold of those from sera of convalescent humans, with mild to moderate, transient, local reactions and systemic events, like fever, pain at the injection site, mild to moderate fatigue and headache (98). The vaccine mRNA-1273 developed by Moderna causes a high level of antibody responses and still shows a dosedependent effect after two vaccinations. The geometric mean titer at the $100 \mu \mathrm{g}$ dose is 2.1 times higher than the titer observed in control convalescent serum specimens after 57 days of vaccination, but solicited adverse events occur common, particularly after the second vaccination of the highest dose (99). More than half of the participants experience solicited systemic and local adverse events, including fatigue, chills, headache, myalgia and pain at the injection site across both vaccinations (99). The above two clinical trials confirm the good effect of the mRNA vaccine and support the further evaluation of them to be candidate vaccines for COVID-19.

In a randomized clinical trial of 103 patients with severe or life-threatening COVID-19, convalescent plasma transfusion therapy does not show statistically significant improvement in the time to clinical improvement (defined as patient discharged alive or reduction of 2 points on a 6-point disease severity scale) within 28 days, compared with the standard treatment group alone (86). And there is no significant difference in 28-day mortality and time from randomization to discharge, while the rate of viral polymerase chain reaction (PCR) results turns from positive at baseline to negative at up to 72 has been greatly improved. It is worth noting that two participants have adverse reactions within a few hours after convalescent plasma transfusion, including chills, rashes, shortness of breath, cyanosis, and severe dyspnea (86). However, several limitations cannot be ignored. Observing clinical improvement takes longer to confirm the response and recovery of severe COVID-19 patients. The quality of the convalescent plasma products, the timing of convalescent 
plasma transfusion and the selection of the patients are all factors that must be considered for subsequent large-scale clinical applications.

We summarized the progress of drug discovery since the epidemic outbreak in Figure 3.

\section{The possibility of the use of MgIG for the treatment of COVID-19}

\section{Antiviral Effect}

SARS-CoV-2, a single-stranded RNA virus, is the third coronavirus causing severe respiratory disease in humans. The two previous coronaviruses, SARS-CoV and MERSCoV, cause SARS (118) and MERS, respectively (119). The structural protein of SARS-CoV-2 is mainly composed of spike protein (S protein), envelope glycoprotein, membrane glycoprotein and nucleocapsid protein. When SARS-CoV-2 infects the host cell, the surface $S$ protein is priming by transmembrane protease serines (TMPRSS2). As a common surface receptor for SARS-CoV and SARS-CoV-2, angiotensin-converting enzyme 2 (ACE2) can combine with the receptor-binding domain (RBD) of $\mathrm{S}$ protein to play its role as a channel for the virus to infect host cells (120). The binding affinity of SARS-CoV-2 to ACE2 is 10-20 times that of SARS-CoV $(121,122)$, which explains the reason why SARS-Cov-2 is more contagious to a certain extent. SARS-CoV-2 and its induced cytokine storm can increase ACE2 expression in host cells, further accelerating viral infection and transmission. Thus, reducing ACE2 expression or inhibiting the bind of ACE2 to the surface spike glycoprotein of the virus may be an effective strategy for blocking viral infection $(121,123)$.

Glycyrrhizic acid compounds with antiviral effects, have been used in the treatment of SARS as early as 2003. Glycyrrhizin is found to inhibit the process of viral replication, adhesion and infection in vero cells and lung epithelial (A549) cell (124-126), these effects may be related to its induction of NO synthase (125). In addition, glycyrrhizin effectively inhibits replication of human immunodeficiency virus (HIV) in cultures of peripheral blood mononuclear cells from HIV-seropositive patients (127). Glycyrrhizic acid also has high antiviral activity against varicella zoster virus, coxsackievirus and enterovirus and rotavirus (128-130). The statistical analysis of herbs and formulae for treating COVID-19 proposes that glycyrrhizic acid compounds have good immunoregulatory and antiviral effects (131). Glycyrrhizin may be combined with ACE2 through molecular docking simulation technology (132). Glycyrrhizic acid metabolizes into glycyrrhetinic acid, which suppresses the expression of androgen target genes TMPRSS2 (133). Moreover, some of important antiviral drugs commonly used in China contain Glycyrrhizin ingredients, such as Lianhua Qingwen capsule, Maxing Shigan decoction and Sijikangbingdu herbal mixture $(23,134-136)$. A case of severe COVID-19 patient with a negative PCR result but a positive antibody test recovers after receiving diammonium glycyrrhizinate and vitamin C replacement therapy (137). These observations suggest that glycyrrhizic acid compounds could be used as potential antiviral drugs by inhibiting the replication, proliferation to take control of the spread of SARS-CoV-2 (22).

As the fourth-generation preparation of glycyrrhizic acid, MgIG hydrolyzes to glycyrrhetinic acid in the body, its structure is similar to steroid hormones. MgIG is often used in the treatment of viral hepatitis. It inhibits the replication of hepatitis virus, showing its better effect than previous generations of glycyrrhizic acid preparations (48-52). ACE2 is expressed in lung, liver, kidney, heart, brain, intestine and other tissue cells, while MgIG has protective effects on these organs and tissues in various disease states. Are these effects related to the inhibition of ACE2? It is worth exploring.

\section{Inbibition of cytokine storm and oxidative stress}

Cytokine storm, also known as cytokine cascade, is an excessive inflammatory response, which often occurs under the influence of external stimuli, such as infection of viruses and bacteria (138). Cytokine storm starts the attack of the immune system on tissues and organs, further causing acute respiratory distress syndrome (ARDS) and multiple organ failure.

SARS-CoV-2 infects the human body, first characterized by increased secretion of early response cytokines such as IL-1, and TNF- $\alpha$, further promoting the secretion of antiinflammatory cytokines to adjust the degree of inflammatory response and maintain immune homeostasis (139). When the balance between pro-inflammatory and anti-inflammatory is broken, early response cytokines could further trigger a series of cytokines' excessive activation and release (such as IL-2, IL-6, IL-8, IL-12, MIP-1 $\alpha$ and MIP-1 $\beta$ ), ultimately causing the out of control of inflammatory response and develop into cytokine storm $(140,141)$. In addition, redox homeostasis generally occurs during viral 


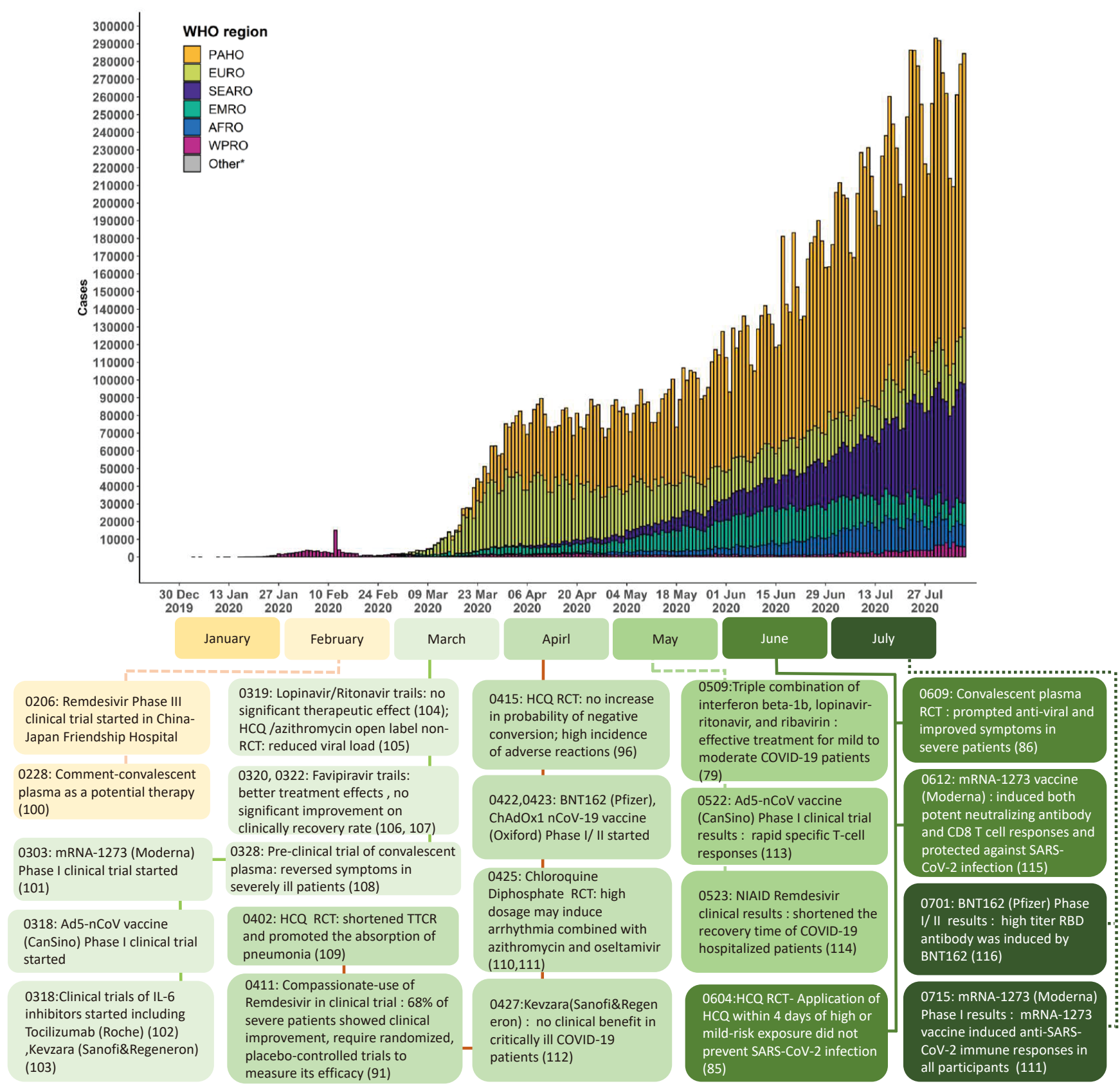

Figure 3 Progress of COVID-19 treatment drugs. As shown above, the therapy and drugs mainly include comment-convalescent plasma, Moderna, CanSino, remdesivir, chloroquine, lopinavir/ratonavir, etc. (79,85,86,91,96,100-116). The column chart above figure 3 is from the WHO report (117). PAHO, Pan American Health Organization; EURO, European Region; SEARO, South-East Asia Region; EMRO, Eastern Mediterranean Region; AFRO, African Region; WPRO, Western Pacific Region; COVID-19, coronavirus disease 2019; Ad5-nCoV, recombinant adenovirus type-5 vectored novel COVID-19; IL-6, interleukin-6; HCQ, hydroxychloroquine; RCT, randomized clinical trial; TTCR, time to clinical recovery; NIAID, national institute of allergy and infectious disease; SARS-CoV-2, severe acute respiratory syndrome coronavirus-2; RBD, receptor binding domain. 
infections, such as human immunodeficiency virus type-1 (HIV-1) (142), hepatitis B virus (143,144), and influenza A virus infection (145). Clinical trials show that COVID-19 patients have high levels of cytokines, also accompanied by oxidative stress in various degrees $(10,146)$. In alveolar type II cells of elderly COVID-19 patients, the redoxactive genes like SOD3, transcription factor 4 (ATF4) and metallothionein 2A (M2TA) are down-regulated significantly (147). Mitochondria dysfunction-mediated oxidative stress is indicated as a key player in COVID-19 pathogenesis and severity $(148,149)$. Thus, the interaction of inflammation and oxidative stress will further worsen the condition of COVID-19 patients.

MgIG has shown anti-inflammatory, antioxidant, and immune-regulating effects as mentioned above. MgIG reduces the production and release of IL- $1 \beta$, IL- 6 and TNF- $\alpha$, and inhibits the migration and activation of neutrophils, resulting in the improvement of inflammatory response and inflammatory cell infiltration of liver, kidney, lung and nervous system $(39,41,46,62,69)$. These results indicate that MgIG may block the further development of the inflammatory response at an early stage of COVID-19. Meanwhile, MgIG significantly decreases NOX1, NOX2 and NOX4 expression $(39,45)$, inhibits ROS and iNOS production, normalizes SOD and MDA level $(39,41,45,57,71)$, therefore, MgIG effectively inhibits oxidative stress response in the body. In terms of mechanism, MgIG may inhibit the activation of inflammation and oxidative pathways, such as TLR4/NF$\kappa \mathrm{B}$, TGF- $\beta 1 / \mathrm{Smad}$, JAK2/STAT3 and p38 MAPK/Akt/ NOX4 signaling pathways $(43,45,68)$.

In general, $\mathrm{MgIG}$ may play a critical role in protecting against pro-inflammatory cytokine-induced inflammation and oxidative stress in different diseases, and it is expected to be an effective drug to ameliorate cytokine storm and restore redox balance for COVID-19.

\section{Improvement of multiple organ damage}

The clinically significant pathological features of COVID-19 patients are lung lesions by computed tomography (CT) scans, including single or multiple ground-glass opacities (GGOs) in the early stage, and then the number of lesions like pulmonary consolidation, and paving appearance is increased in the later stage $(150,151)$. Histopathologic examination of lung biopsy tissues reveals diffuse alveolar damage and interstitial fibrosis (152), proteinaceous exudate, edema, focal reactive hyperplasia of pneumocytes with patchy inflammatory cellular infiltration, and multinucleated giant cells (153). Glycyrrhizin as an inhibitor of high mobility group box-1(HMGB1) attenuates pulmonary hypertension $(154,155)$ and acute lung injury $(156,157)$. MgIG significantly inhibits inflammation response and oxidative stress, reduces collagen deposition and slows down the process of pulmonary fibrosis. Its action mechanism may be related to the regulation of TGF- $\beta$, NF$\kappa \mathrm{B}$ and MAPK pathways $(43,45,158)$.

In addition to the damage of the respiratory system, clinical evidence shows that COVID-19 patients have a very high proportion of organ damage including liver, kidney, heart, brain or others, and the cause of this condition may have a certain relevance to ACE2 expressed widely in body (17). Among 99 COVID-19 patients, 43 patients have abnormal liver function, and 7 patients have different degrees of kidney injury (146). In the early study report of 41 patients, about $12 \%$ of patients have acute myocardial injury (7), usually with abnormal myocardial enzymes (159). Among the 52 patients with severe novel pneumonia, 12 of them suffer heart damage and 9 of them have died (160). Equally importantly, the abnormal mental behavior of COVID-19 patients cannot be ignored (161). The latest pathological results obtained from systematic autopsy (37 cases) and percutaneous multiple organ biopsy ("minimally invasive autopsy", 54 cases), show multiple organs with different extent of acute injury in lung, liver, spleen, kidney, heart, etc. Detected by PCR, immunohistochemistry and transmission electron microscopy, SARS-CoV-2 infection are found in lung, liver, heart, kidney, spleen, etc., possibly resulting in direct organ injury by inducing lymphocyte degeneration, necrosis, macrophage proliferation, and neutrophil infiltration (162). Additionally, brain hyperemia and edema, partial neuron degeneration, and ischemic changes are detected in nervous system of these patients (162). These observations make it clear that SARS$\mathrm{CoV}-2$ not only attacks the respiratory system to cause pneumonia and respiratory failure, but also drive injury and even failure of multiple organs.

As showed in Figure 2, MgIG improves liver injury induced by various factors, decreases oxidative stress and inflammatory response, normalizes AST, ALT and DBIL levels, and restores liver function $(54-57,67-71,163)$. For kidney injury, MgIG stabilizes the structure of podocytes to reduce proteinuria, pro-inflammatory response and oxidative stress $(38,41,75)$. Moreover, MgIG improves the contraction of myocardial cells, inhibits myocardial hypertrophy and fibrosis (74). MgIG also enhances 


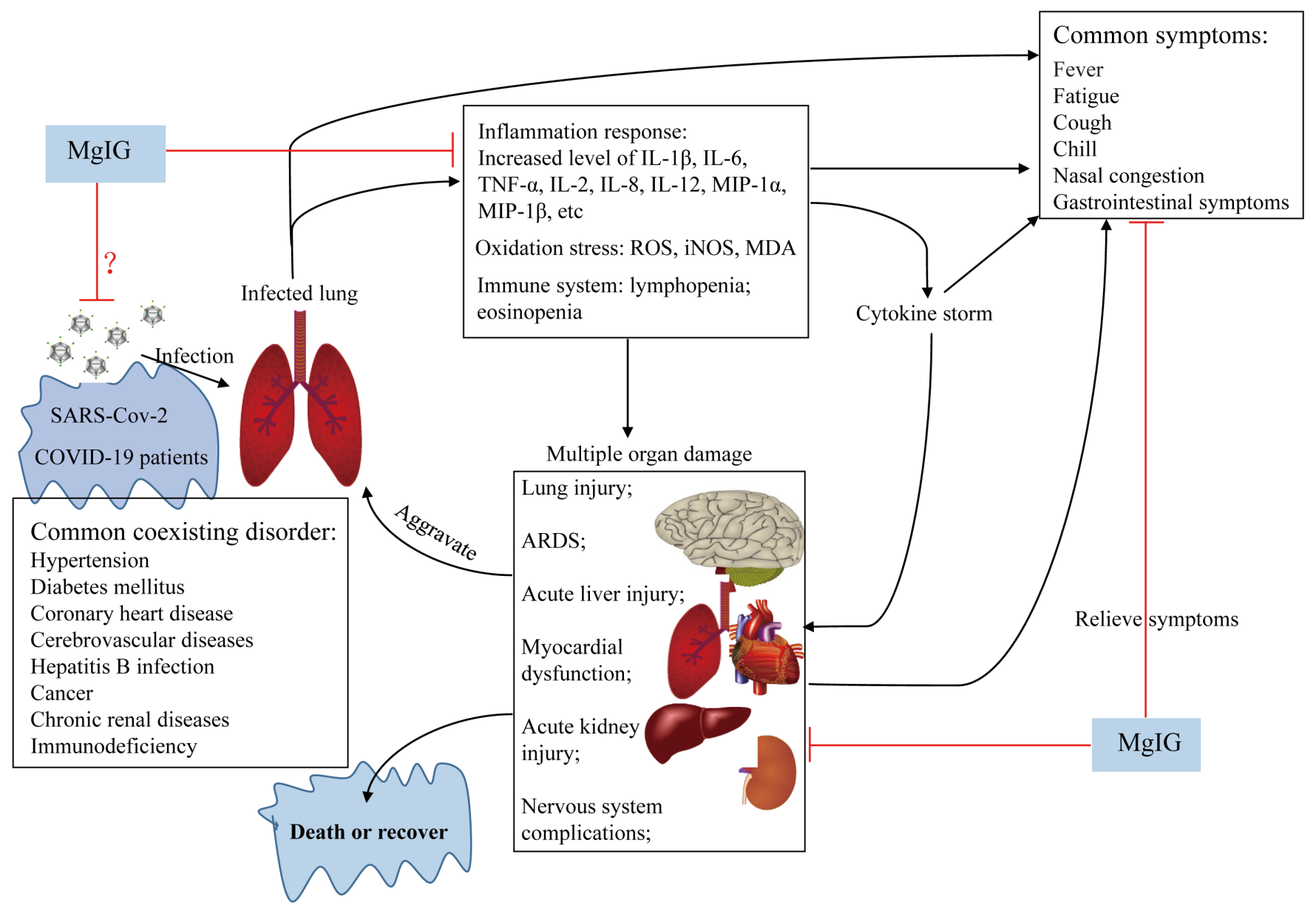

Figure 4 Summary of action modes of magnesium isoglycyrrhizinate. MgIG, magnesium isoglycyrrhizinate; SARS-CoV-2, Severe acute respiratory syndrome coronavirus -2; COVID-19, coronavirus disease 2019; IL-1 $\beta$, interleukin-1 $\beta$; TNF- $\alpha$, tumor necrosis factor- $\alpha$; ROS, reactive oxygen species; MIP-1 $\alpha$, macrophage inflammatory protein 1 alpha; iNOS, inducible nitric oxide synthase; MDA, malondialdehyde; ARDS, acute respiratory distress syndrome.

cognitive ability and improves depression-like behavior $(46,47)$. Therefore, MgIG could ameliorate the multiple organ damage caused by the infection of SARS-CoV-2.

Based on the clinical efficacy and basic research results of MgIG mentioned above, the application of MgIG in this program may ameliorate cytokine storm and oxidative stress induced by the SARS-CoV-2 infection of host cells, reduce the injury of multiple organs in COVID-19 patients. Here, we summarized the full text related to action modes of MgIG shown in Figure 4. In the "Management Standard for Mild and Common Patients of Coronavirus Disease 2019 (COVID-19) (Second Edition)" issued by the National Health Commission of the People's Republic of China, the intravenous drip solution of MgIG is included in supportive treatment. MgIG $150-200 \mathrm{mg}$ is added to $250 \mathrm{~mL}$ of $5 \%$ glucose, intravenous drip, once a day, 7 to 14 days as a course of treatment.

\section{Safety}

According to the drug instructions and clinical experiences, the daily dosage of $\mathrm{MgIG}$ for adult patients is between 100-200 mg, generally not more than $200 \mathrm{mg}$. In elderly patients, the dosage of $\mathrm{MgIG}$ is also within the above range $(164,165)$, but there is no clear clinical dosage instruction for pregnant women. $\mathrm{MgIG}(25 \mathrm{mg}$ iv, qd) is often used in combination with ganciclovir for the treatment of infant cytomegalovirus hepatitis, significantly improving the 
infant's liver function, reducing the viral load, and being able to improve symptom with fewer adverse reaction $(166,167)$. In children with severe hand-foot-mouth disease and associated liver injury, MgIG injection (3-5 mg/kg.iv, qd) significantly decreases serum ALT and AST levels, and restores normal liver function (168). Moreover, MgIG injection (100 mg iv, qd) can reduce serum levels of IL-7, chemokine (C-X-C motif) ligand 8 (CXCL8) and CXCL10 in children with autoimmune hepatitis, and inhibit inflammation caused by excessive immune response (169).

In addition to the different dosages for different ages, the compatibility of $\mathrm{MgIG}$ with some drugs requires special attention in clinic. The mixture of $15 \mathrm{mg}$ ambroxol hydrochloride injection and $100 \mathrm{mg} \mathrm{MgIG}$ injection produces white flocs (170). Similarly, after mixing $100 \mathrm{~mL}$ ciprofloxacin lactate sodium chloride injection and $150 \mathrm{mg}$ MgIG injection, white flocs and sediments appear immediately, which do not disappear after shaking, and there is no change after $24 \mathrm{~h}$ (171). However, these have not been proved whether this adverse phenomenon will cause adverse reactions to the human body. In addition, when combined with injections such as ademetionine 1,4-butanedisulfonate, sodium ferulate, pazufloxacin mesylate, etc., similar phenomena also exist $(163,172,173)$. Combination of drugs is common in clinical practice, but drug interactions are prone to occur. The flocculation produced by the combination of MgIG injection and other drugs for COVID-19 patients indicates that the compatibility between these drugs is poor. There may be a chemical reaction, which is prone to adverse reaction. In addition, these concentrations of drug combination will also be affected. When this happens, it is recommended to stop the medication (MgIG injection combined with other drugs) and adopt a separate interval administration method for COVID-19 patients.

Clinical studies have found that increased or longterm use of glycyrrhizic acid preparations may induce pseudoaldosteronism, mainly manifested as hypokalemia, increased blood pressure, sodium, fluid retention, edema, weight gain and other pseudo-aldosterone symptoms (174). The pseudoaldosteronism caused by glycyrrhizic acid preparations is mainly related to $18-\beta$ isomer. The target organ distribution of $18-\alpha$ and $18-\beta$ isomers is different. The concentration of $18-\alpha$ isomer is significantly higher than that of $18-\beta$ isomer in the liver, but lower than $18-\beta$ isomer in the kidney in rats (175). At the same time, $18-\beta$ isomer inhibits the activity of $11 \beta$-hydroxysteroid dehydrogenase (11 $\beta$-OHSD) more obviously in rat kidney. As a result of hypokalemia, symptoms such as fatigue, low muscle strength and arrhythmia may occur in patients (hypertension or heart failure) (176). Therefore, it is necessary to fully observe the determination of serum potassium, and stop the administration when abnormality is detected. The $18 \alpha$-isomer glycyrrhizic acid can also inhibit $11 \beta$-OHSD activity, resulting in a decrease of serum potassium ion concentration, but compared with $18 \beta$ isomer, its effect is significantly weaker in guinea pigs and rats. The main adverse reaction of glycyrrhizic acid preparations is the inhibitory effect of renal $11 \beta-O H S D$, while $18 \alpha$-glycyrrhizic acid stereoisomers contained as high as $98 \%$ in $\mathrm{MgIG}$ has very little effect on renal $11 \beta$-OHSD $(177,178)$. Consistently, MgIG injection (100, 150, and $200 \mathrm{mg}$ iv, qd) have no side effects of pseudoaldosteronism in the phase 2 and 3 clinical studies of viral hepatitis and acute liver injury according to the description in the drug's instructions (179).

In addition to pseudoaldosteronism, there are some other adverse reactions in clinical trials, but the incidence is low. In the phase III clinical trial of 332 cases of viral hepatitis dominated by Chia Tai Tianqing Pharmaceutical Group, there is one case each of palpitations, eyelid edema, dizziness, rash, and vomiting with the treatment of MgIG injection $(100,150 \mathrm{mg}$ iv, qd) (179). In the phase III clinical trial of MgIG injection (200 $\mathrm{mg}$ iv, qd) on acute drug-induced liver injury, 14 out of 354 patients have adverse reactions, mainly including palpitations, allergies, hypokalemia, abnormal liver function indicators, etc. The above symptoms are mild and tolerable. A number of clinical studies have confirmed the safety of MgIG injection (180-183). The meta-analysis results of clinical trials also show that the incidence of adverse drug reactions in patients in the MgIG injection treatment group is significantly lower than that of other glycyrrhizic acid preparations (184). However, clinical trials have the limitations. Phase I clinical trial shows the safety of MgIG injection, but the supporting populations are all from China. For people from other countries, further experiments and clinical evidence are needed (185). And as mentioned above, the Phase III clinical trial of MgIG led by Chia Tai Tianqing is mainly for patients with viral hepatitis, and lacks universality for other types of hepatitis (179).

In general, MgIG is safe for clinical use. During the treatment with MgIG, blood pressure as well as serum potassium and sodium concentrations should be checked 
regularly. The combined use of $\mathrm{MgIG}$ with thiazides such as etanic acid and furosemide, antihypertensive diuretics such as triclosan and chlorthalidone, may increase potassium excretion, therefore, it is necessary to monitor serum potassium.

As a drug with higher effectiveness and safety in glycyrrhizic acid preparations, $\mathrm{MgIG}$ is widely used clinically. MgIG has a low probability of adverse reactions when used within a safe dose, but attention should be paid to the compatibility of contraindications and changes in potassium ion concentration. For COVID-19 patients, the adjuvant treatment of MgIG will improve the multiple processes from SARS-CoV-2 infection to organ injury, and slow down the disease process in all directions to restore the patient's health. MgIG has been used as a therapeutic drug in the clinical treatment of COVID-19 in China. The effective dose of MgIG, specific treatment plans and precautions need to be continuously tried and summarized in the clinic.

\section{Conclusions}

The COVID-19 epidemic is serious and has a high mortality rate. More than 87 million cases of COVID-19 and over 1 million deaths have been reported as of January 7 , 2021. All countries in the world are facing great challenges. Therefore, the active implementation of effective treatment is very important. MgIG has anti-inflammatory, antioxidative, anti-viral, and immunomodulatory effects, protecting liver, kidney, heart, lung, brain, and other organs from damage under disease conditions. MgIG injection as a mature drug is used to treat hepatic disorders for a long time. This narrative review provides the evidence supporting the recommended MgIG as supportive therapy in the "Management Standard for Mild and Common Patients of Coronavirus Disease 2019 (COVID-19) (Second Edition)", which is jointly issued by National Health Commission of People's Republic of China and National Administration of Traditional Chinese Medicine. MgIG may help shorten the course of COVID-19 patients, effectively curb the transition from mild and common patients to severe and critical illnesses, prevent organ failure and reduce mortality. Therefore, MgIG is expected to play an active role in the clinical practice of the prevention and treatment of COVID-19.

\section{Acknowledgments}

Funding: This paper was supported by grants from National
Key R\&D Program of China [2019YFC1711000]; and Special Funding for Emergency Research on COVID-19 in Nanjing University [No. 020814380135].

\section{Footnote}

Reporting Checklist: The authors have completed the Narrative review checklist. Available at http://dx.doi. org/10.21037/apm-20-1971

Peer Review File: Available at http://dx.doi.org/10.21037/ apm-20-1971

Conflicts of Interest: All authors have completed the ICMJE uniform disclosure form (available at http://dx.doi. org/10.21037/apm-20-1971). The authors have no conflicts of interest to declare.

Ethical Statement: The authors are accountable for all aspects of the work in ensuring that questions related to the accuracy or integrity of any part of the work are appropriately investigated and resolved.

Open Access Statement: This is an Open Access article distributed in accordance with the Creative Commons Attribution-NonCommercial-NoDerivs 4.0 International License (CC BY-NC-ND 4.0), which permits the noncommercial replication and distribution of the article with the strict proviso that no changes or edits are made and the original work is properly cited (including links to both the formal publication through the relevant DOI and the license). See: https://creativecommons.org/licenses/by-nc-nd/4.0/.

\section{References}

1. Wiersinga WJ, Rhodes A, Cheng AC, et al. Pathophysiology, transmission, diagnosis, and treatment of coronavirus disease 2019 (COVID-19): a review. JAMA 2020;324:782-93.

2. Pan Y, Zhang D, Yang P, et al. Viral load of SARS-CoV-2 in clinical samples. Lancet Infect Dis 2020;20:411-2.

3. Chen $\mathrm{G}, \mathrm{Wu} \mathrm{D}$, Guo $\mathrm{W}$, et al. Clinical and immunological features of severe and moderate coronavirus disease 2019. J Clin Invest 2020;130:2620-9.

4. Liu J, Li S, Liu J, et al. Longitudinal characteristics of lymphocyte responses and cytokine profiles in the peripheral blood of SARS-CoV-2 infected patients. EBioMedicine 2020;55:102763. 
5. Huang KJ, Su IJ, Theron M, et al. An interferon-gammarelated cytokine storm in SARS patients. J Med Virol 2005;75:185-94.

6. Zhou J, Chu H, Li C, et al. Active replication of Middle East respiratory syndrome coronavirus and aberrant induction of inflammatory cytokines and chemokines in human macrophages: implications for pathogenesis. J Infect Dis 2014;209:1331-42.

7. Huang C, Wang Y, Li X, et al. Clinical features of patients infected with 2019 novel coronavirus in Wuhan, China. Lancet 2020;395:497-506.

8. Grasselli G, Pesenti A, Cecconi M. Critical care utilization for the COVID-19 outbreak in Lombardy, Italy: early xxperience and forecast during an emergency response 2020;323:1545-6.

9. Guan WJ, Ni ZY, Hu Y, et al. Clinical characteristics of coronavirus disease 2019 in China. N Engl J Med 2020;382:1708-20.

10. Wang D, Hu B, Hu C, et al. Clinical characteristics of 138 hospitalized patients with 2019 novel noronavirus-infected pneumonia in Wuhan, China. JAMA 2020;323:1061-9.

11. Zhang JJ, Dong X, Cao YY, et al. Clinical characteristics of 140 patients infected with SARS-CoV-2 in Wuhan, China. Allergy 2020;75:1730-41.

12. Cai Q, Huang D, Yu H, et al. COVID-19: abnormal liver function tests. J Hepatol 2020;73:566-74.

13. Shi S, Qin M, Shen B, et al. Association of cardiac injury with mortality in hospitalized patients with COVID-19 in Wuhan, China. JAMA Cardiol 2020;5:802-10.

14. Cheng Y, Luo R, Wang K, et al. Kidney disease is associated with in-hospital death of patients with COVID-19. Kidney Int 2020;97:829-38.

15. Du Y, Tu L, Zhu P, et al. Clinical features of 85 fatal cases of COVID-19 from Wuhan. a retrospective observational study. Am J Respir Crit Care Med 2020;201:1372-9.

16. Jin X, Lian JS, Hu JH, et al. Epidemiological, clinical and virological characteristics of 74 cases of coronavirusinfected disease 2019 (COVID-19) with gastrointestinal symptoms. Gut 2020;69:1002-9.

17. Gupta A, Madhavan MV, Sehgal K, et al. Extrapulmonary manifestations of COVID-19. Nat Med 2020;26:1017-32.

18. Lamers MM, Beumer J, van der Vaart J, et al. SARS$\mathrm{CoV}-2$ productively infects human gut enterocytes. Science 2020;369:50-4.

19. He LL, Gong P, FangY, et al. Analysis on application of Chinese materia medica in treatment of COVID-19 by suppressing cytokine storm. Chinese Traditional and Herbal Drugs 2020;51:1375-85.
20. Du HZ, Hou XY, Miao YH, et al. Traditional Chinese medicine: an effective treatment for 2019 novel coronavirus pneumonia (NCP). Chin J Nat Med 2020;18:206-10.

21. Yang Y, Islam MS, Wang J, et al. Traditional Chinese Medicine in the treatment of patients infected with 2019new coronavirus (SARS-CoV-2): a review and perspective. Int J Biol Sci 2020;16:1708-17.

22. Luo P, Liu D, Li J. Pharmacological perspective: glycyrrhizin may be an efficacious therapeutic agent for COVID-19. Int J Antimicrob Agents 2020;55:105995.

23. Bailly C, Vergoten G. Glycyrrhizin: an alternative drug for the treatment of COVID-19 infection and the associated respiratory syndrome? Pharmacol Ther 2020;214:107618.

24. Murck H. Symptomatic protective action of glycyrrhizin (licorice) in COVID-19 infection? Front Immunol 2020;11:1239.

25. Sinha SK, Prasad SK, Islam MA, et al. Identification of bioactive compounds from Glycyrrhiza glabra as possible inhibitor of SARS-CoV-2 spike glycoprotein and nonstructural protein-15: a pharmacoinformatics study. J Biomol Struct Dyn 2020:1-15.

26. Yang R, Liu H, Bai C, et al. Chemical composition and pharmacological mechanism of Qingfei Paidu decoction and Ma Xing Shi Gan decoction against coronavirus disease 2019 (COVID-19): in silico and experimental study. Pharmacol Res 2020;157:104820.

27. Zhao X, Jiang Y, Zhao Y, et al. Analysis of the susceptibility to COVID-19 in pregnancy and recommendations on potential drug screening. Eur J Clin Microbiol Infect Dis 2020;39:1209-20.

28. $\mathrm{Pu} \mathrm{JY}, \mathrm{He} \mathrm{L}, \mathrm{Wu} \mathrm{SY}$, et al. Anti-virus research of triterpenoids in licorice. Bing Du Xue Bao 2013;29:673-9.

29. Khan R, Rehman MU, Khan AQ, et al. Glycyrrhizic acid suppresses 1,2-dimethylhydrazine-induced colon tumorigenesis in Wistar rats: alleviation of inflammatory, proliferation, angiogenic, and apoptotic markers. Environ Toxicol 2018;33:1272-83.

30. Sahin F, Oznurhan F. Antibacterial efficacy and remineralization capacity of glycyrrhizic acid added casein phosphopeptide-amorphous calcium phosphate. Microsc Res Tech 2020;83:744-54.

31. Xu X, Gong L, Wang B, et al. Glycyrrhizin attenuates salmonella enterica serovar typhimurium infection: new insights into its protective mechanism. Front Immunol 2018;9:2321.

32. Li Y, Liu T, Yan C, et al. Diammonium glycyrrhizinate protects against nonalcoholic fatty liver disease in mice through modulation of gut microbiota and restoration of 
intestinal barrier. Mol Pharm 2018;15:3860-70.

33. Li M, Wen Z, Xue Y, et al. Cardioprotective effects of glycyrrhizic acid involve inhibition of calcium influx via L-type calcium channels and myocardial contraction in rats. Naunyn Schmiedebergs Arch Pharmacol 2020;393:979-89.

34. Orazizadeh M, Khorsandi L, Mansouri E, et al. The effect of glycyrrhizin acid on Bax and Bcl2 expression in hepatotoxicity induced by Titanium dioxide nanoparticles in rats. Gastroenterol Hepatol Bed Bench 2020;13:168-76.

35. Tan QY, Hu Q, Zhu SN, et al. Licorice root extract and magnesium isoglycyrrhizinate protect against triptolideinduced hepatotoxicity via up-regulation of the Nrf2 pathway. Drug Deliv 2018;25:1213-23.

36. PubChem 2019 update [Internet]. U.S. National Library of Medicine. Compound CID: 14982; 139032961. [cited 2020 Sep 28]. Available online: https://pubchem.ncbi.nlm. nih.gov/

37. Jiang $\mathrm{W}, \mathrm{Xu} \mathrm{S}$, Guo $\mathrm{H}$, et al. Magnesium isoglycyrrhizinate prevents the nonalcoholic hepatic steatosis via regulating energy homeostasis. J Cell Mol Med 2020;24:7201-13.

38. Li TS, Chen L, Wang SC, et al. Magnesium isoglycyrrhizinate ameliorates fructose-induced podocyte apoptosis through downregulation of miR-193a to increase WT1. Biochem Pharmacol 2019;166:139-52.

39. Yang YZ, Liu ZH, Wang SC, et al. Magnesium isoglycyrrhizinate alleviates fructose-induced liver oxidative stress and inflammatory injury through suppressing NOXs. Eur J Pharmacol 2020;883:173314.

40. Li P, Li S, Gu H, et al. The exposure-effect-toxicity correlation of docetaxel and magnesium isoglycyrrhizinate in non-small cell lung tumor-bearing mice. Biomed Pharmacother 2018;97:1000-10.

41. Zhao Z, Tang Z, Zhang W, et al. Magnesium isoglycyrrhizinate protects against renal-ischemiareperfusion injury in a rat model via anti-inflammation, anti-oxidation and anti-apoptosis. Mol Med Rep 2017;16:3627-33.

42. Movafagh S, Crook S, Vo K. Regulation of hypoxiainducible factor-1a by reactive oxygen species: new developments in an old debate. J Cell Biochem 2015;116:696-703.

43. Ma D, Zhang J, Zhang Y, et al. Inhibition of myocardial hypertrophy by magnesium isoglycyrrhizinate through the TLR4/NF- $\kappa \mathrm{B}$ signaling pathway in mice. Int Immunopharmacol 2018;55:237-44.

44. Xiao ZW, Zhang W, Ma L, et al. Therapeutic effect of magnesium isoglycyrrhizinate in rats on lung injury induced by paraquat poisoning. Eur Rev Med Pharmacol Sci 2014;18:311-20.

45. Yang Q, Zhang P, Liu T, et al. Magnesium isoglycyrrhizinate ameliorates radiation-induced pulmonary fibrosis by inhibiting fibroblast differentiation via the p38MAPK/Akt/NOX4 pathway. Biomed Pharmacother 2019;115:108955.

46. Jiang W, Guo H, Su D, et al. Ameliorative effect of magnesium isoglycyrrhizinate on hepatic encephalopathy by Epirubicin. Int Immunopharmacol 2019;75:105774.

47. Jiang W, Chen Q, Li P, et al. Magnesium isoglycyrrhizinate attenuates lipopolysaccharide-induced depressive-like behavior in mice. Biomed Pharmacother 2017;86:177-84.

48. Zhang SY. Efficacy of magnesium isolycyrrhizinate combined with telbivudine in treatment of patients with chronic hepatitis. Guide of China Medicine 2011;9:76-7.

49. Li HL. Curative effect of magnesium isoglycyrrhizinate in combination with lamivudine on chronic hepatitis B. Anhui Medical and Pharmaceutical Journal 2010;14:209-10.

50. Yan ZH, Wang YM, Tang B, et al. Meta-analysis of magnesium isoglycyrrhizinate combined with nucleoside analogues in patients with chronic hepatitis B. Zhonghua Gan Zang Bing Za Zhi 2014;22:108-12.

51. Fang YY. Comparative analysis on glycyrrhizin and magnesium isoglycyrrhizinate in treatment of viral hepatitis. China Health Standard Management 2017;8:89-90.

52. Li HQ, Guo Y. Clinical effect of magnesium isoglycyrrhizinate in the treatment of chronic viral hepatitis Chronic Pathematology Journal 2018;19:960-1.

53. Li XM. Analysis of the outcome of magnesium isoglycyrrhizinate combined with adefovir intreatment of patients with chronic hepatitis B. Journal of Youjiang Mediacl University For Nationalities 2012;34:624-5.

54. Tang LN, Lin F, Shen Z, et al. Magnesium isoglycyrrhizinate used in the treatment of chemotherapeutic drugs-induced acute liver dysfunction: A phase III clinical trial. Tumor 2012;32:738-43.

55. Wang Y, Wang Z, Gao M, et al. Efficacy and safety of magnesium isoglycyrrhizinate injection in patients with acute drug-induced liver injury: a phase II trial. Liver Int 2019;39:2102-11.

56. Cao Y, Shi H, Sun Z, et al. Protective effects of magnesium glycyrrhizinate on methotrexate-induced hepatotoxicity and intestinal toxicity may be by reducing COX-2. Front Pharmacol 2019;10:119.

57. Zou X, Wang Y, Peng C, et al. Magnesium isoglycyrrhizinate has hepatoprotective effects in an 
oxaliplatin-induced model of liver injury. Int J Mol Med 2018;42:2020-30.

58. Wu Z, Zhang Y, Song T, et al. Magnesium isoglycyrrhizinate ameliorates doxorubicin-induced acute cardiac and hepatic toxicity via anti-oxidant and anti-apoptotic mechanisms in mice. Exp Ther Med 2018;15:1005-12.

59. Jiang W, Liu J, Li P, et al. Magnesium isoglycyrrhizinate shows hepatoprotective effects in a cyclophosphamideinduced model of hepatic injury. Oncotarget 2017;8:33252-64.

60. Jia M. Therapeutic Efficacy of Reduced Glutathione Combined with Magnesium Isoglycyrrhizinate for Alcoholic Liver Disease. China Pharmacy 2011;22:718-9.

61. Chen XQ, Wang P. Effects of magnesium isoglycyrrhizinate combined with reduced glutathione for alcoholic hepatitis. Journal of Community Medicine 2014;12:41-3.

62. Wang Y, Zhang Z, Wang X, et al. Amelioration of ethanolinduced hepatitis by magnesium isoglycyrrhizinate through inhibition of neutrophil cell infiltration and oxidative damage. Mediators Inflamm 2017;2017:3526903.

63. Lu C, Xu W, Shao J, et al. Blockade of hedgehog pathway is required for the protective effects of magnesium isoglycyrrhizinate against ethanol-induced hepatocyte steatosis and apoptosis. IUBMB Life 2017;69:540-52.

64. Sui M, Jiang X, Chen J, et al. Magnesium isoglycyrrhizinate ameliorates liver fibrosis and hepatic stellate cell activation by regulating ferroptosis signaling pathway. Biomed Pharmacother 2018;106:125-33.

65. Bian M, Chen X, Zhang C, et al. Magnesium isoglycyrrhizinate promotes the activated hepatic stellate cells apoptosis via endoplasmic reticulum stress and ameliorates fibrogenesis in vitro and in vivo. Biofactors 2017;43:836-46.

66. Tee JK, Peng F, Tan YL, et al. Magnesium isoglycyrrhizinate ameliorates fibrosis and disrupts TGF$\beta$-mediated Smad pathway in activated hepatic stellate cell line LX2. Front Pharmacol 2018;9:1018.

67. Li L, Zhou J, Li Q, et al. The inhibition of Hippo/ Yap signaling pathway is required for magnesium isoglycyrrhizinate to ameliorate hepatic stellate cell inflammation and activation. Biomed Pharmacother 2018;106:83-91.

68. Yang YZ, Zhao XJ, Xu HJ, et al. Magnesium isoglycyrrhizinate ameliorates high fructose-induced liver fibrosis in rat by increasing miR-375-3p to suppress JAK2/STAT3 pathway and TGF- $\beta 1 /$ Smad signaling. Acta
Pharmacol Sin 2019;40:879-94.

69. Zhao XJ, Yang YZ, Zheng YJ, et al. Magnesium isoglycyrrhizinate blocks fructose-induced hepatic NF- B/ NLRP3 inflammasome activation and lipid metabolism disorder. Eur J Pharmacol 2017;809:141-50.

70. Yang Q, Wang J, Liu R, et al. Amelioration of concanavalin A-induced autoimmune hepatitis by magnesium isoglycyrrhizinate through inhibition of CD4(+)CD25(-) CD69(+) subset proliferation. Drug Des Devel Ther 2016;10:443-53.

71. Mei F, Yu J, Li M, et al. Magnesium isoglycyrrhizinate alleviates liver injury in obese rats with acute necrotizing pancreatitis. Pathol Res Pract 2019;215:106-14.

72. Oka T, Akazawa H, Naito AT, et al. Angiogenesis and cardiac hypertrophy: maintenance of cardiac function and causative roles in heart failure. Circ Res 2014;114:565-71.

73. Smith KM, Squiers J. Hypertrophic cardiomyopathy: an overview. Crit Care Nurs Clin North Am 2013;25:263-72.

74. Lin Y, Zhang Y, Song Q, et al. Magnesium isoglycyrrhizinate inhibits L-type $\mathrm{Ca}(2+)$ channels, $\mathrm{Ca}(2+)$ transients, and contractility but not hERG K(+) channels. Arch Pharm Res 2017;40:1135-45.

75. Zhou WX, Lu GL. The effect of magnesium isoglycyrrhizinate in the treatment of hemorrhagic fever with renal syndrome accompanied with liver injury. Chinese Journal of Biochemical Pharmaceutics 2012;33:463-5.

76. Wu A, Peng Y, Huang B, et al. Genome composition and divergence of the novel coronavirus (2019-nCoV) originating in China. Cell Host Microbe 2020;27:325-8.

77. Zhu N, Zhang D, Wang W, et al. A novel coronavirus from patients with pneumonia in China, 2019. N Engl J Med 2020;382:727-33.

78. Ramiro S, Mostard RLM, Magro-Checa C, et al. Historically controlled comparison of glucocorticoids with or without tocilizumab versus supportive care only in patients with COVID-19-associated cytokine storm syndrome: results of the CHIC study. Ann Rheum Dis 2020;79:1143-51.

79. Hung IF, Lung KC, Tso EY, et al. Triple combination of interferon beta-1b, lopinavir-ritonavir, and ribavirin in the treatment of patients admitted to hospital with COVID-19: an open-label, randomised, phase 2 trial. Lancet 2020;395:1695-704.

80. Irie K, Nakagawa A, Fujita $H$, et al. Pharmacokinetics of favipiravir in critically Ill patients with COVID-19. Clin Transl Sci 2020;13:880-5.

81. Deftereos SG, Giannopoulos G, Vrachatis DA,et al. 
Effect of colchicine vs standard care on cardiac and inflammatory biomarkers and clinical outcomes in patients hospitalized with coronavirus disease 2019: the GRECCO-19 randomized clinical trial. JAMA Netw Open 2020;3:e2013136.

82. Damle B, Vourvahis M, Wang E, et al. Clinical pharmacology perspectives on the antiviral activity of azithromycin and use in COVID-19. Clin Pharmacol Ther 2020;108:201-11.

83. Liu F, Zhu Y, Zhang J, et al. Intravenous high-dose vitamin C for the treatment of severe COVID-19: study protocol for a multicentre randomised controlled trial. BMJ Open 2020;10:e039519.

84. Wang Y, Zhang D, Du G, et al. Remdesivir in adults with severe COVID-19: a randomised, double-blind, placebocontrolled, multicentre trial. Lancet 2020;395:1569-78.

85. Boulware DR, Pullen MF, Bangdiwala AS, et al. A randomized trial of hydroxychloroquine as postexposure prophylaxis for COVID-19. N Engl J Med 2020;383:517-25.

86. Li L, Zhang W, Hu Y, et al. Effect of Convalescent Plasma Therapy on Time to Clinical Improvement in Patients With Severe and Life-threatening COVID-19: A Randomized Clinical Trial. JAMA 2020;324:460-70. Erratum in: JAMA 2020;324:519.

87. Lo MK, Feldmann F, Gary JM, et al. Remdesivir (GS5734) protects African green monkeys from Nipah virus challenge. Sci Transl Med 2019;11:eaau9242.

88. Lo MK, Jordan R, Arvey A, et al. GS-5734 and its parent nucleoside analog inhibit Filo-, Pneumo-, and Paramyxoviruses. Sci Rep 2017;7:43395.

89. Sheahan TP, Sims AC, Graham RL, et al. Broad-spectrum antiviral GS-5734 inhibits both epidemic and zoonotic coronaviruses. Sci Transl Med 2017;9:eaal3653.

90. Warren TK, Jordan R, Lo MK, et al. Therapeutic efficacy of the small molecule GS-5734 against Ebola virus in rhesus monkeys. Nature 2016;531:381-5.

91. Grein J, Ohmagari N, Shin D, et al. Compassionate use of remdesivir for patients with severe COVID-19. N Engl J Med 2020;382:2327-36.

92. Williamson BN, Feldmann F, Schwarz B, et al. Clinical benefit of remdesivir in rhesus macaques infected with SARS-CoV-2. Nature 2020;585:273-6.

93. Ferner RE, Aronson JK. Chloroquine and hydroxychloroquine in COVID-19. BMJ 2020;369:m1432.

94. Yazdany J, Kim AHJ. Use of hydroxychloroquine and chloroquine during the COVID-19 pandemic: what every clinician should know. Ann Intern Med 2020;172:754-5.
95. Saleh M, Gabriels J, Chang D, et al. Effect of chloroquine, hydroxychloroquine, and azithromycin on the corrected QT interval in patients with SARS-CoV-2 infection. Circ Arrhythm Electrophysiol 2020;13:e008662.

96. Tang W, Cao Z, Han M, et al. Hydroxychloroquine in patients with mainly mild to moderate coronavirus disease 2019: open label, randomised controlled trial. BMJ 2020;369:m1849.

97. Graham BS. Rapid COVID-19 vaccine development. Science 2020;368:945-6.

98. Mulligan MJ, Lyke KE, Kitchin N, et al. Phase $1 / 2$ study to describe the safety and immunogenicity of a COVID-19 RNA vaccine candidate (BNT162b1) in adults 18 to 55 years of age: interim report. medRxiv 2020:2020.06.30.20142570.

99. Jackson LA, Anderson EJ, Rouphael NG, et al. An mRNA vaccine against SARS-CoV-2 - preliminary report. N Engl J Med 2020;383:1920-31.

100. Chen L, Xiong J, Bao L, et al. Convalescent plasma as a potential therapy for COVID-19. Lancet Infect Dis 2020;20:398-400.

101. Safety and Immunogenicity Study of 2019-nCoV Vaccine (mRNA-1273) for Prophylaxis of SARS-CoV-2 Infection (COVID-19) [Internet]. National Institute of Allergy and Infectious Diseases (NIAID): ClinicalTrials.gov, U.S. National Library of Medicine; 2020. [cited 2020 Sep 28]. Available online: https://clinicaltrials.gov/ct2/show/NCT0 4283461 ? cond $=$ nct $04283461 \&$ draw $=2 \&$ rank $=1$

102.Xu X, Han M, Li T, et al. Effective treatment of severe COVID-19 patients with tocilizumab. Proc Natl Acad Sci U S A 2020;117:10970-5.

103.Jason Mast. Covid-19 roundup: Fred Hutch cuts down further on lab work, Roche joins Regeneron and Sanofi in IL-6 trials, China orders a vaccine effort. Endpointsnews 2020 March 19; Available online: https://endpts.com/ covid-19-roundup-fred-hutch-cuts-down-further-on-labwork-roche-joins-regeneron-and-sanofi-in-il-6-trialschina-orders-a-vaccine-effort/

104. Cao B, Wang Y, Wen D, et al. A Trial of LopinavirRitonavir in Adults Hospitalized with Severe Covid-19. N Engl J Med 2020;382:1787-99.

105. Gautret P, Lagier JC, Parola P, et al. Hydroxychloroquine and azithromycin as a treatment of COVID-19: results of an open-label non-randomized clinical trial. Int J Antimicrob Agents 2020;56:105949.

106. Cai Q, Yang M, Liu D, et al. Experimental Treatment with Favipiravir for COVID-19: An Open-Label Control Study. Engineering (Beijing) [Preprint]. [Posted 2020 Mar 
18; cited 2020 Sep 28]. Available online: https://www. engineering.org.cn/ch/10.1016/j.eng.2020.03.007

107. Chen C, Zhang Y, Huang JY, et al. Favipiravir versus Arbidol for COVID-19: A Randomized Clinical Trial. medRxiv 2020.03.17.20037432 [Preprint]. [Posted 2020 Apr 15; cited 2020 Sep 28]. Available online: https://www. medrxiv.org/content/10.1101/2020.03.17.20037432v4

108. Shen C, Wang Z, Zhao F, et al. Treatment of 5 Critically Ill Patients With COVID-19 With Convalescent Plasma. JAMA 2020;323:1582-9.

109. Chen ZW, Hu JJ, Zhang ZW, et al. Efficacy of hydroxychloroquine in patients with COVID-19: results of a randomized clinical trial. medRxiv 2020.03.22.20040758 [Preprint]. [Posted 2020 Apr 10; cited 2020 Sep 28] Available online: https://www.medrxiv.org/content/10.110 1/2020.03.22.20040758v3

110. Borba MGS, Val FFA, Sampaio VS, et al. Effect of High vs Low Doses of Chloroquine Diphosphate as Adjunctive Therapy for Patients Hospitalized With Severe Acute Respiratory Syndrome Coronavirus 2 (SARS-CoV-2) Infection: A Randomized Clinical Trial. JAMA Netw Open 2020;3:e208857.

111. Chorin E, Dai M., Shulman E, et al. The QT interval in patients with COVID-19 treated with hydroxychloroquine and azithromycin. Nat Med 2020, 26: 808-9.

112. Evaluation of the Efficacy and Safety of Sarilumab in Hospitalized Patients With COVID-19 [Internet]. National Institute of Allergy and Infectious Diseases (NIAID): ClinicalTrials.gov, U.S. National Library of Medicine; 2020. [cited 2020 Sep 28]. Available online: https://clinicaltrials.gov/ct2/show/NCT04315298? term=r egeneron\&draw $=2$

113.Zhu FC, Li YH, Guan XH, et al. Safety, tolerability, and immunogenicity of a recombinant adenovirus type5 vectored COVID-19 vaccine: a dose-escalation, openlabel, non-randomised, first-in-human trial. Lancet 2020;395:1845-54.

114. Beigel JH, Tomashek KM, Dodd LE, et al. Remdesivir for the Treatment of Covid-19 - Preliminary Report. N Engl J Med 2020;383:994.

115. Corbett KS, Edwards DK, Leist SR, et al. SARS-CoV-2 mRNA vaccine design enabled by prototype pathogen preparedness. Nature 2020;586:567-71.

116. Mulligan MJ, Lyke KE, Kitchin N, et al. Phase 1/2 study of COVID-19 RNA vaccine BNT162b1 in adults. Nature 10.1038/s41586-020-2639-4. [Preprint]. [Posted 2020 Aug 12; cited 2020 Sep 28]. Available online: https://www. nature.com/articles/s41586-020-2639-4
117. World Health Organization. (2020, August 8).

Coronavirus disease (COVID-19) situation reports August 2020-Situation Report-201. Available online: https://www.who.int/docs/default-source/coronaviruse/ situation-reports/20200808-covid-19-sitrep-201. pdf?sfvrsn=121bb855_2

118.Zhong NS, Zheng BJ, Li YM, et al. Epidemiology and cause of severe acute respiratory syndrome (SARS) in Guangdong, People's Republic of China, in February, 2003. Lancet 2003;362:1353-8.

119. Fisman DN, Tuite AR. The epidemiology of MERS-CoV. Lancet Infect Dis 2014;14:6-7.

120.Hoffmann M, Kleine-Weber H, Schroeder S, et al. SARSCoV-2 cell entry depends on ACE2 and TMPRSS2 and is blocked by a clinically proven protease inhibitor. Cell 2020;181:271-80.e8.

121. Wrapp D, Wang N, Corbett KS, et al. Cryo-EM structure of the 2019-nCoV spike in the prefusion conformation. Science 2020;367:1260-3.

122. Yan R, Zhang Y, Li Y, et al. Structural basis for the recognition of SARS-CoV-2 by full-length human ACE2. Science 2020;367:1444-8.

123.Zhuang MW, Cheng Y, Zhang J, et al. Increasing host cellular receptor-angiotensin-converting enzyme 2 expression by coronavirus may facilitate $2019-\mathrm{nCoV}$ (or SARS-CoV-2) infection. J Med Virol 2020;92:2693-701.

124.Fujii T, Nakamura T, Iwamoto A. Current concepts in SARS treatment. J Infect Chemother 2004;10:1-7.

125. Cinatl J, Morgenstern B, Bauer G, et al. Glycyrrhizin, an active component of liquorice roots, and replication of SARS-associated coronavirus. Lancet 2003;361:2045-6.

126. Michaelis M, Geiler J, Naczk P, et al. Glycyrrhizin exerts antioxidative effects in $\mathrm{H} 5 \mathrm{~N} 1$ influenza A virus-infected cells and inhibits virus replication and pro-inflammatory gene expression. PLoS One 2011;6:e19705.

127. Sasaki H, Takei M, Kobayashi M, et al. Effect of glycyrrhizin, an active component of licorice roots, on HIV replication in cultures of peripheral blood mononuclear cells from HIV-seropositive patients. Pathobiology 2002;70:229-36.

128. Wang J, Chen X, Wang W, et al. Glycyrrhizic acid as the antiviral component of Glycyrrhiza uralensis Fisch. against coxsackievirus A16 and enterovirus 71 of hand foot and mouth disease. J Ethnopharmacol 2013;147:114-21.

129. Shebl RI, Amin MA, Emad-Eldin A, et al. Antiviral activity of liquorice powder extract against varicella zoster virus isolated from Egyptian patients. Chang Gung Med J 2012;35:231-9. 
130.Kwon HJ, Kim HH, Ryu YB, et al. In vitro anti-rotavirus activity of polyphenol compounds isolated from the roots of Glycyrrhiza uralensis. Bioorg Med Chem 2010;18:7668-74.

131.Luo L, Jiang JW, Wang C, et al. Analysis on herbal medicines utilized for treatment of COVID-19. Acta Pharm Sin B 2020;10:1192-204.

132. Chen HS, Du QH. Potential natural compounds for preventing SARS-CoV-2 (2019-nCoV) infection. Preprints 2020010358 [Preprint]. [Posted 2020 January 30; cited 2020 Sep 28]. Available online: https://www.preprints.org/ manuscript/202001.0358/v2

133.Sun Y, Jiang M, Park PH, et al. Transcriptional suppression of androgen receptor by $18 \beta$-glycyrrhetinic acid in LNCaP human prostate cancer cells. Arch Pharm Res 2020;43:433-48.

134.Jia W, Wang C, Wang Y, et al. Qualitative and quantitative analysis of the major constituents in Chinese medical preparation Lianhua-Qingwen capsule by UPLC-DADQTOF-MS. ScientificWorldJournal 2015;2015:731765.

135. Li DM, Qi RH, Zhang HC, et al. Clinical application evaluation and revision suggestions of clinical practice guideline on traditional Chinese medicine therapy alone or combined with antibiotics for community acquired pneumonia. Zhongguo Zhong Yao Za Zhi 2018;43:4759-64.

136. Yao Z, Yu J, Tang Z, et al. Multi-evaluating strategy for Siji-kangbingdu mixture: chemical profiling, fingerprint characterization, and quantitative analysis. Molecules 2019;24:3545.

137. Ding H, Deng W, Ding L, et al. Glycyrrhetinic acid and its derivatives as potential alternative medicine to relieve symptoms in nonhospitalized COVID-19 patients. J Med Virol 2020;92:2200-4.

138. Chousterman BG, Swirski FK, Weber GF. Cytokine storm and sepsis disease pathogenesis. Semin Immunopathol 2017;39:517-28.

139.Pedersen SF, Ho YC. SARS-CoV-2: a storm is raging. J Clin Invest 2020;130:2202-5.

140.Cavalli G, Dinarello CA. Suppression of inflammation and acquired immunity by IL-37. Immunol Rev 2018;281:179-90.

141. Gadina M, Gazaniga N, Vian L, et al. Small molecules to the rescue: inhibition of cytokine signaling in immunemediated diseases. J Autoimmun 2017;85:20-31.

142.Ivanov AV, Valuev-Elliston VT, Ivanova ON, et al. Oxidative stress during HIV infection: mechanisms and consequences. Oxid Med Cell Longev 2016;2016:8910396.

143. Chen X, Hu Y, Zhang W, et al. Cisplatin induces autophagy to enhance hepatitis $\mathrm{B}$ virus replication via activation of ROS/JNK and inhibition of the Akt/mTOR pathway. Free Radic Biol Med 2019;131:225-36.

144. Yu X, Lan P, Hou X, et al. HBV inhibits LPS-induced NLRP3 inflammasome activation and IL-1 $\beta$ production via suppressing the NF- $\mathrm{BB}$ pathway and ROS production. J Hepatol 2017;66:693-702.

145. Vlahos R, Stambas J, Selemidis S. Suppressing production of reactive oxygen species (ROS) for influenza A virus therapy. Trends Pharmacol Sci 2012;33:3-8.

146. Chen N, Zhou M, Dong X, et al. Epidemiological and clinical characteristics of 99 cases of 2019 novel coronavirus pneumonia in Wuhan, China: a descriptive study. Lancet 2020;395:507-13.

147.Abouhashem AS, Singh K, Azzazy HME, et al. Is low alveolar type II cell SOD3 in the lungs of elderly linked to the observed severity of COVID-19? Antioxid Redox Signal 2020;33:59-65.

148. Saleh J, Peyssonnaux C, Singh KK, et al. Mitochondria and microbiota dysfunction in COVID-19 pathogenesis. Mitochondrion 2020;54:1-7.

149. Delgado-Roche L, Mesta F. Oxidative stress as key player in severe acute respiratory syndrome coronavirus (SARSCoV) infection. Arch Med Res 2020;51:384-7.

150.Pan F, Ye T, Sun P, et al. Time course of lung changes at chest CT during recovery from coronavirus disease 2019 (COVID-19). Radiology 2020;295:715-21.

151.Song F, Shi N, Shan F, et al. Emerging 2019 novel coronavirus (2019-nCoV) pneumonia. Radiology 2020;295:210-7.

152.Zhang H, Zhou P, Wei Y, et al. Histopathologic changes and SARS-CoV-2 immunostaining in the lung of a patient with COVID-19. Ann Intern Med 2020;172:629-32.

153. Tian S, Hu W, Niu L, et al. Pulmonary pathology of earlyphase 2019 novel coronavirus (COVID-19) pneumonia in two patients with lung cancer. J Thorac Oncol 2020;15:700-4.

154. Dai M, Xiao R, Cai L, et al. HMGB1 is mechanistically essential in the development of experimental pulmonary hypertension. Am J Physiol Cell Physiol 2019;316:C175-85.

155. Yang PS, Kim DH, Lee YJ, et al. Glycyrrhizin, inhibitor of high mobility group box-1, attenuates monocrotalineinduced pulmonary hypertension and vascular remodeling in rats. Respir Res 2014;15:148.

156. Qu L, Chen C, He W, et al. Glycyrrhizic acid ameliorates LPS-induced acute lung injury by regulating autophagy through the PI3K/AKT/mTOR pathway. Am J Transl Res 2019;11:2042-55. 
157. Yao L, Sun T. Glycyrrhizin administration ameliorates Streptococcus aureus-induced acute lung injury. Int Immunopharmacol 2019;70:504-11.

158.Xie C, Li X, Zhu J, et al. Magnesium isoglycyrrhizinate suppresses LPS-induced inflammation and oxidative stress through inhibiting NF- $\kappa \mathrm{B}$ and MAPK pathways in RAW264.7 cells. Bioorg Med Chem 2019;27:516-24.

159.Xu H, Hou K, Xu R, et al. Clinical characteristics and risk factors of cardiac involvement in COVID-19. J Am Heart Assoc 2020;9:e016807.

160. Yang X, Yu Y, Xu J, et al. Clinical course and outcomes of critically ill patients with SARS-CoV-2 pneumonia in Wuhan, China: a single-centered, retrospective, observational study. Lancet Respir Med 2020;8:475-81.

161. Mao L, Jin H, Wang M, et al. Neurologic manifestations of hospitalized patients with coronavirus disease 2019 in Wuhan, China. JAMA Neurol 2020;77:683-90.

162. Bian XW. Autopsy of COVID-19 patients in China. National Science Review 2020;7:1414-8.

163. Tang YS, Kang A, Zhang SH, et al. Adverse drug reactions and incompatibility induced by ademetionine 1,4-butanedisulfonate for injection. China Pharmaceuticals 2019;28:67-70.

164. Yan GJ. Clinical observation on the prevention of liver injury caused by chemotherapy with GP regimen in elderly patients with lung cancer by magnesium isoglycyrrhizinate. Chinese Community Doctors 2017;33:83-4.

165.Jin YL, Qiu XG. Effects of magnesium isoglycyrrhizinate in the elderly with drug-induced liver injury. Practical Geriatrics 2015;29:119-20.

166. Yan N. Therapeutic effects of ganciclovir combined with magnesium isoglycyrrhizinate for cytomegalovirus hepatitis in infants. Journal of Pediatric Pharmacy 2012;19:20-2.

167.Li L, Cai XH, Chen WF, et al. Effects research on magnesuim isoglycyrrhizinate in the treatment of infant cytomegalovirus hepatitis. Chinese Journal of Health Laboratory Technology 2016;26:1570-1.

168.Zhou WL, Xing XW. An analysis about treatment of severe hand-foot-and-mouth disease and associated liver injury with using the magnesium isoglycyrrhizinate injection. Guide of China Medicine 2012;10:30-1.

169. Du Y, Jiang ZH, Wu YL. Efficacy of tripterygium wilfordii polyglycosides and magnesium isoglycyrrhizinate combination in the treatment of children with autoimmune hepatitis. Journal of Practical Hepatology 2020;23:348-51.

170.Xie HL. A contraindication between magnesium isoglycyrrhizinate injection and ambroxol hydrochloride injection. Journal of Military Surgeon in Southwest China 2017;19:190-200.

171. Yang CY, Sun D. A contraindication between ciprofloxacin lactate and sodium chloride injection and magnesium isoglycyrrhizinate injection. Journal of Nursing 2010;17:38.

172. Ye R. A contraindication between sodium ferulate injection and magnesium isoglycyrrhizinate injection. Chinese Journal of Practical Nursing 2013;29:21.

173.Xi L. A contraindication between pazufloxacin mesylate injection and magnesium isoglycyrrhizinate injection. Chinese Journal of Practical Nursing 2012;28:41.

174. Komatsu A, Yoshino T, Suzuki T, et al. Risk factors associated with pseudoaldosteronism in patients with chronic hepatitis: a retrospective cohort study. Basic Clin Pharmacol Toxicol 2019;124:607-14.

175.Zeng CX, Yang Q, Hu Q. A comparison of the distribution of two glycyrrhizic acid epimers in rat tissues. Eur J Drug Metab Pharmacokinet 2006;31:253-8.

176. Krämer BK, Endemann D. Cardiac risks of hypokalemia and hypomagnesemia. Ther Umsch 2000;57:398-9.

177.Lou JY. Inhibitory effects of $\alpha$-glycyrrhizic acid on $11 \beta$-hydroxysteroid dehydrogenase. Chinese Journal of Modern Applied Pharmacy 2005;27:263-5.

178. Xu R, Xiao Q, Cao Y, et al. Comparison of the exposure of glycyrrhizin and its metabolites and the pseudoaldosteronism after intravenous administration of alpha- and beta-glycyrrhizin in rat. Drug Res (Stuttg) 2013;63:620-4.

179. Chia Tai TianQing. The Instructions of Magnesium Isoglycyrrhizinate Injection [Internet]. Chia Tai Tian Qing Pharmaceutical Co., Ltd 2014, cited 2020 Oct 24. Available online: https://www.cttq.com/product/baogandetail-6009.htm

180.Song QY, Wang WL, Lu Y. Clinical observation of magnesium isoglycyrrhizinate combined with somatostatin in treatment of liver cirrhosis. Drug Evaluation Research 2019;43:725-8.

181.Han RX. Comparison of Clinical effects between magnesium isoglycyrrhizinate and glycyrrhizin in the treatment of patients with viral hepatitis. China \&Foreign Medical Treatment 2020;39:130-2.

182.Li D. Clinical observation of magnesium isoglycolate in the treatment of liver injury caused by hepatic artery embolization and chemotherapy for liver cancer. Chinese Community Doctors 2019;35:12-3.

183. Mao YM, Zeng MD, Chen Y, et al. Magnesium isoglycyrrhizinate in the treatment of chronic liver 
diseases: a randomized, double-blind, multi-doses, active drug controlled, multi-center study. Zhonghua Gan Zang Bing Za Zhi 2009;17:847-51.

184.Zhang ZW, Xie XC, Chen JJ, et al. Meta-analysis on effectiveness and safety of magnesium isoglycyrrhizinate for drug-induced liver injury. Pharmacy Today

Cite this article as: Tang C, Ding H, Sun Y, Han Z, Kong L. A narrative review of COVID-19: magnesium isoglycyrrhizinate as a potential adjuvant treatment. Ann Palliat Med 2021;10(4):47774798. doi: 10.21037/apm-20-1971
2019;29:453-60.

185. Sun L, Shen J, Pang X, et al. Phase I safety and pharmacokinetic study of magnesium isoglycyrrhizinate after single and multiple intravenous doses in chinese healthy volunteers. J Clin Pharmacol 2007;47:767-73. 